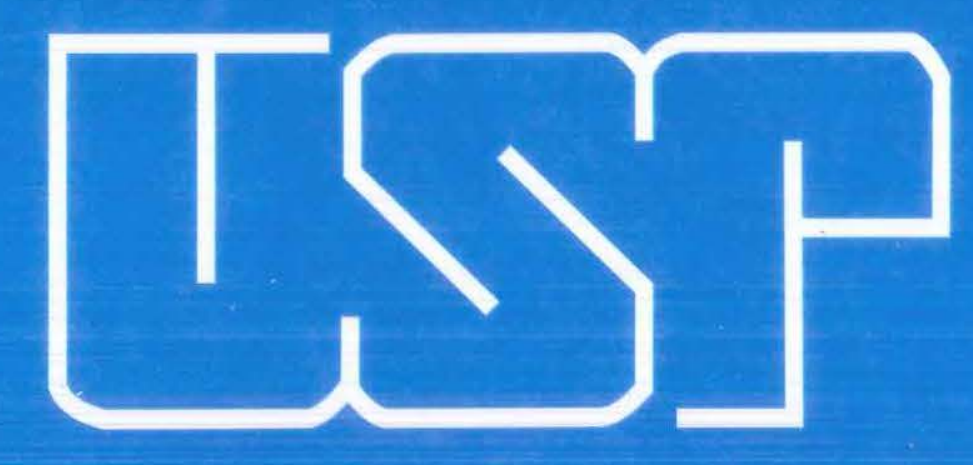

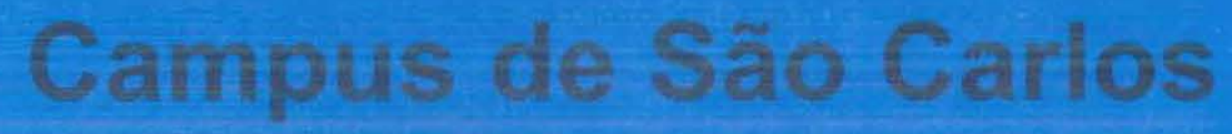

VISUALIZAÇÃO CIENTÍFICA COMPUTACIONAL APLICADA A MODELOS AERODINÂMICOS SIMULADOS EM METODO DOS PAINÉIS

LUCIANA ABDO LINS DE ALBUQUERQUE Prof. Dr. Michael George Maunsell

UNIVERSIDADE DE SÃO PAULO 


\section{VISUALIZAÇÃO CIÊNTIFICA COMPUTACIONAL APLICADA A MODELOS AERODINÂMICOS SIMULADOS EM MÉTODO DOS PAINÉIS.}

Luciana Abdo Lins de Albuquerque

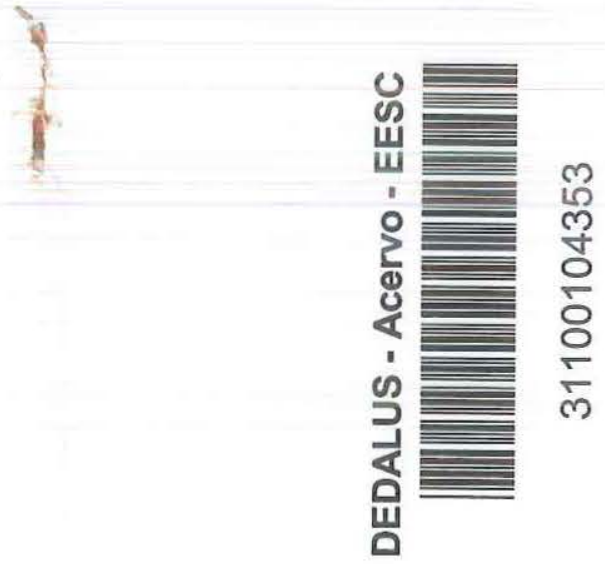

Dissertação apresentada à Escola de Engenharia de São Carlos da Universidade de São Paulo, como parte dos requisitos para obtenção do título de Mestre em Engenharia Mecânica

Serviço de Pós-Graduação EESC/USPMaunsell

\section{EXEMPLAR REVISADO}

Data de entrada no Serviço....................../.20.8. Ass...............tentix.

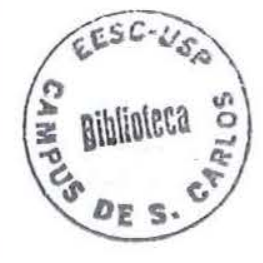

São Carlos

2003 
Dissertação defendida e julgada em 17-11-2003 perante a Comissão Julgadora:

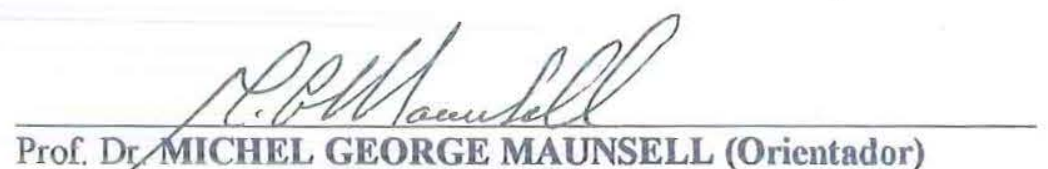

(Escola de Engenharia de São Carlos/USP)
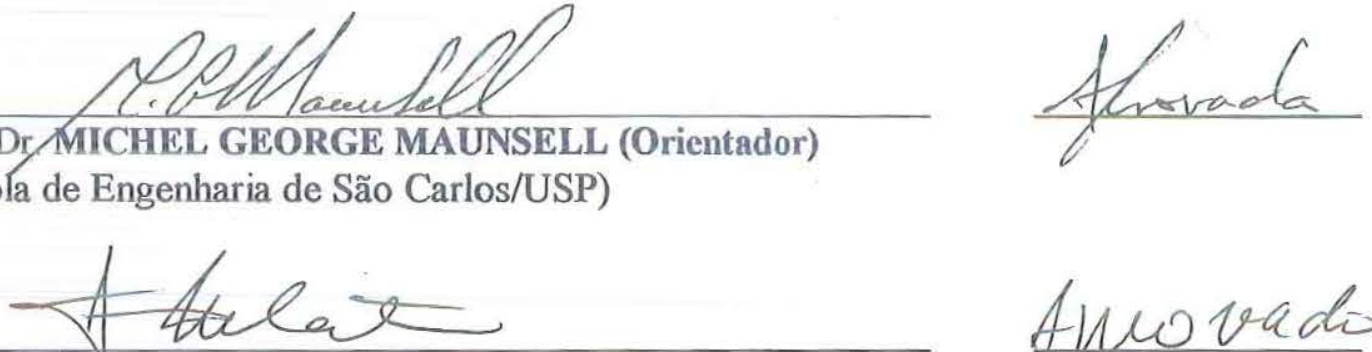

Prof. Assoc. IFERNANDO MARTINI CATALANO

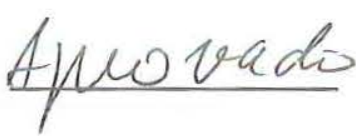

(Escola de Engenharia de São Carlos/USP)

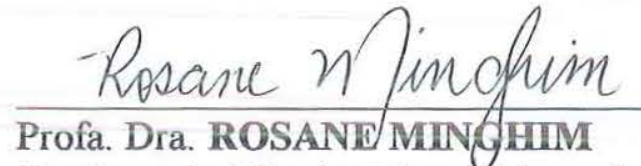

(Instituto de Ciências Matemática e de Computação/ICMC)
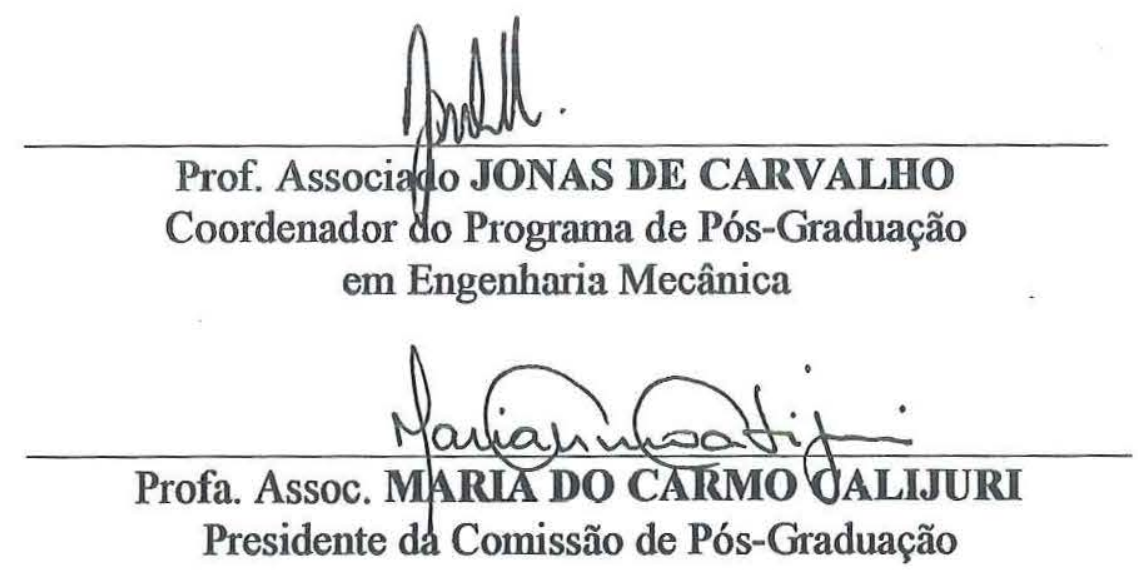
Á minha querida familia, pai, mãe, irmão e irmã que sempre me incentivaram e torceram por mim. 


\section{AGRADECIMENTOS}

Ao Prof. Mike, pela amizade, bondade e orientação.

À CAPES, pelo suporte financeiro para o desenvolvimento deste trabalho.

À Universidade de São Paulo, seus funcionário e docentes que colaboram de forma expressiva e eficiente com o desenvolvimento de pesquisas e de novas tecnologias para o futuro do país.

Aos amigos, João Marcelo, José Antonio e Dawson pela ajuda incondicional e amizade sem os quais este trabalho não teria amadurecido.

Ao meu marido André, por sua dedicação, companheirismo e cumplicidade neste período. 
"Uma coisa que eu aprendi ao longo da vida: que toda nossa ciência, comparada com a realidade, é primitiva e infantil - e, ainda assim, é a coisa mais preciosa que temos". 


\section{SUMÁRIO}

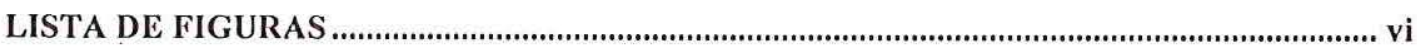

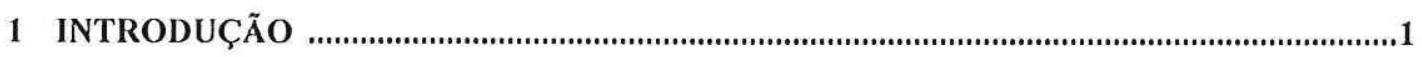

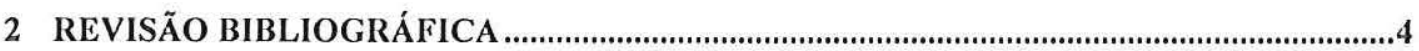

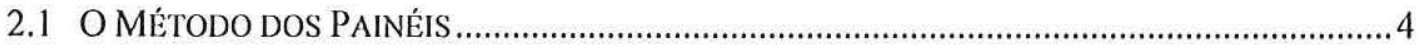

2.1.1. HiSTÓRICO: (ORIGEM E EVOLUÇূ̃o DOS MÉTOdOS DE PAINÉIS).............................. 4

2.1.2. ASPECTOS PARTICULARES AOS MÉTODOS DE PAINÉIS............................................

2.1.3. APLICAÇÃO DE MÉTODO DE PAINÉIS EM CONFIGURAÇÕES AERONÁUTICAS............8

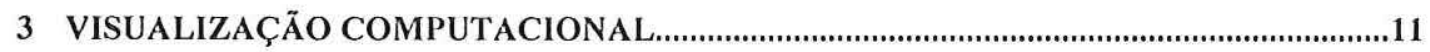

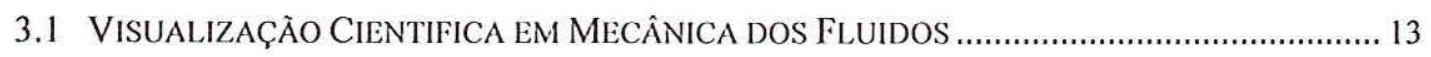

3.1.1. VISUALIZAÇÃO DE CAMPOS ESCALARES ................................................................ 14

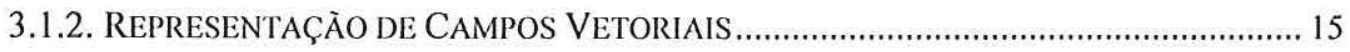

3.1.2.1.REPRESENTAÇÕES VETORIAIS LOCAIS ...................................................... 17

3.1.2.2. REPRESENTAÇÕES VETORIAIS GLOBAIS ................................................... 17

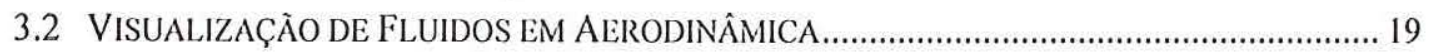

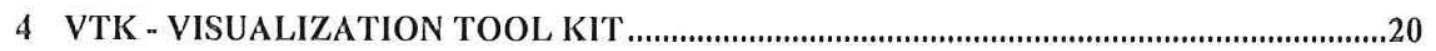

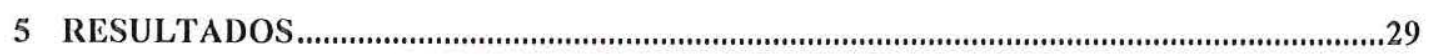

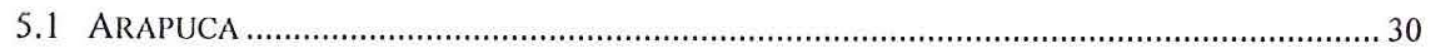

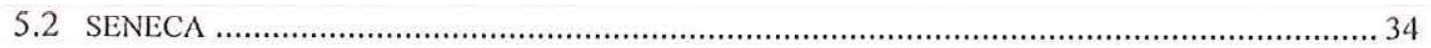

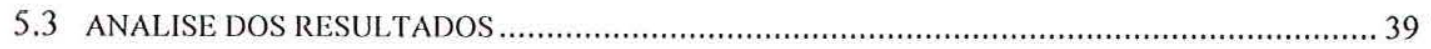

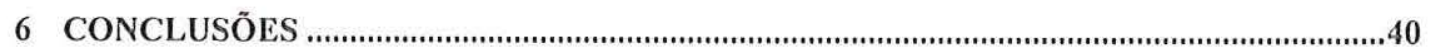

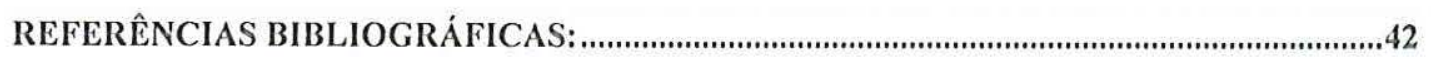
APÊNDICE A - O MÉTODO DE IMPLEMENTAÇÃO DO PANFLO 2.0

APÊNDICE B - MANUAIS 


\section{LISTA DE FIGURAS}

FIGURA 2.1.2.1. - PONTO DE CONTROLE E VERSOR NORMAL SOBRE UM PAINEL QUADRILATERAL. .......7

FIGURA 3.1. - EXEMPLO DE APLICAÇÒES (À ESQUERDA, EM METEOROLOGIA; $\dot{A}$ DIREITA, EM

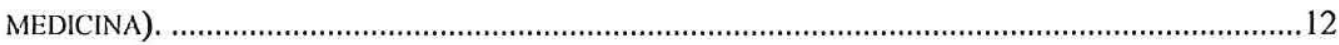

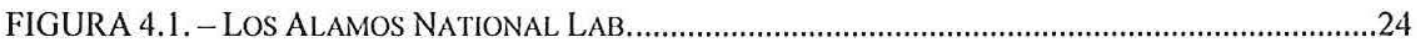

FIGURA 4.2. - THE VIRTUAL CREATURES PROJECT - STANFORD UNIVERSITY....................................24

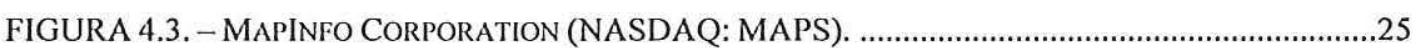

FIGURA 4.4. - UNIVERSIDADE DO PORTO - PORTUGAL ........................................................................22

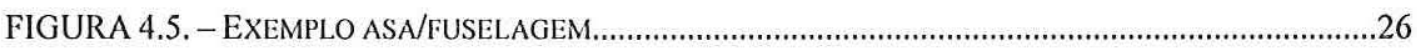

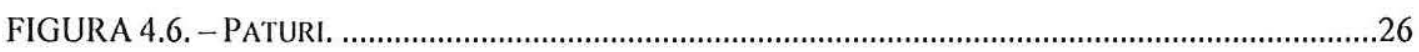

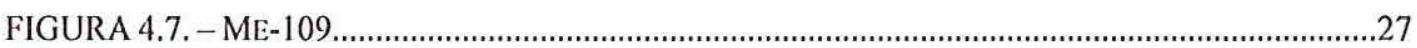

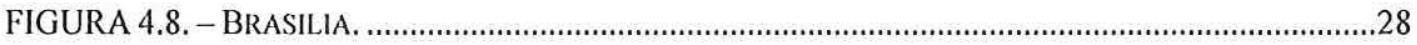

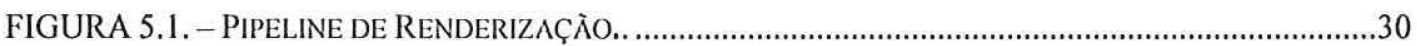

FIGURA 5.2. - DESENHO ESQUEMÁTICO DA AERONAVE ARAPUCA .....................................................

FIGURA 5.3. - ASAS DA AERONAVE ARAPUCA COM ALPHA $=0$ (À ESQUERDA EXTRADORSO E À DIREITA

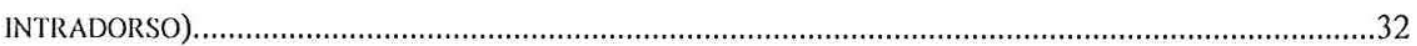

FIGURA 5.4. - ASAS DA AERONAVE ARAPUCA COM ALPHA $=5$ (À ESQUERDA EXTRADORSO E À DIREITA

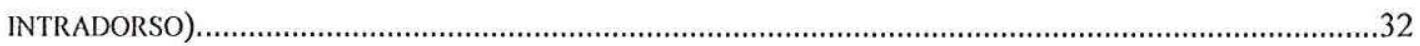

FIGURA 5.5. - ASAS DA AERONAVE ARAPUCA COM ALPHA $=10$ ( $\grave{\lambda}$ ESQUERDA EXTRADORSO E $\dot{A}$

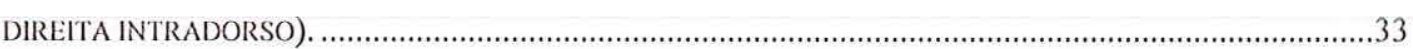

FIGURA 5.6. - ASAS DA AERONAVE ARAPUCA COM ALPHA=15 (À ESQUERDA EXTRADORSO E $\dot{A}$

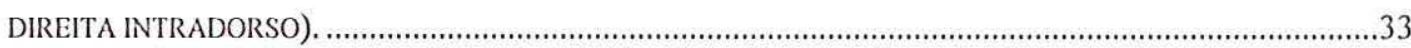

FIGURA 5.7. - DESENHO ESQUEMÁTICO DO MEIO-MODELO SENECA _...................................................

FIGURA 5.8. - ASA DO MODELO COM ALPHA =0 (VISTA DO BORDO DE ATAQUE) ................................35

FIGURA 5.9. - ASA DO MODELO COM ALPHA =5 (VISTA DO BORDO DE ATAQUE) ...................................35

FIGURA 5.10. - ASA DO MODELO COM ALPHA=10 (VISTA DO BORDO DE ATAQUE)................................36

FIGURA 5.11. - ASA DO MODELO COM ALPHA=15 (VISTA DO BORDO DE ATAQUE).............................36

FIGURA 5.12. - ASA DO MODELO COM ALPHA=0 (À ESQUERDA EXTRADORSO E $\dot{A}$ DIREITA INTRADORSO)

FIGURA 5.13. - ASA DO MODELO COM ALPHA $=5$ (À ESQUERDA EXTRADORSO E $\dot{A}$ DIREITA INTRADORSO)

FIGURA 5.14. - ASA DO MODELO COM ALPHA=10 (À ESQUERDA EXTRADORSO E Ȧ DIREITA INTRADORSO)

FIGURA 5.15. - ASA DO MODELO COM ALPHA $=15$ (À ESQUERDA EXTRADORSO E Ȧ DIREITA INTRADORSO) 


\section{RESUMO}

ALBUQUERQUE, L.A.L., (2003). Visualização Cientifica Computacional Aplicada a Modelos Aerodinâmicos simulados em Método dos Painéis. São Carlos, 2003. 43p. Dissertação (Mestrado) - Escola de Engenharia de São Carlos, Universidade de São Paulo.

O aumento do poder computacional e conseqüente desenvolvimento das técnicas de simulação numérica, aliados ao avanço tecnológico dos periféricos de medição, fizeram com que muitas áreas de pesquisa, passassem a necessitar de ferramentas gráficas e de auxilio computacional para apoiar o processo de interpretação das informações geradas. A Aplicação de técnicas gráficas para ampliar a capacidade de interpretação de dados científicos tem sido denominada Visualização em Computação Cientifica (ViSCVisualization in Scientific Computing). Modelos aerodinâmicos construídos no laboratório, foram simulados em software numérico de Método dos Painéis e submetidos a rotinas desenvolvidas em $\mathrm{C}++$ as quais serviram de superfície para uma ferramenta do tipo biblioteca, de baixo custo, muito utilizada em Universidades do mundo todo, chama VTK (Visualization Tool Kit), que possui elementos gráficos para a geração de visualizações de qualquer tipo de dados. Esses códigos em $\mathrm{C}++$ são responsáveis pelos tipos de visualização gerados e principalmente por permitir o uso da ferramenta. As visualizações de distribuição de pressão e isolinhas nas superfícies dos modelos são de suma importância na identificação de problemas aerodinâmicos possibilitando correçốes e modificações antes mesmo de o modelo ser construído. 


\section{ABSTRACT}

ALBUQUERQUE, L.A.L., (2003). Open Source Visualization of Scientific Computational Development to Aircrafts Models simulated in Method of the Panels. São Carlos, 2003. 43p. Master Degree - Escola de Engenharia de São Carlos, Universidade de São Paulo.

The increase of computational power and the technical development of numerical simulation are responsible for the creation of many new areas that use graphics tools and computational aid for the interpretation of the information generated. The application of graphics techniques to increase the capability of scientific interpretation is called ViSC or Visualization in Scientific Computation. Laboratory built freeflight and wind tunnel models were calculate using numerical software and submitted to routines developed in $\mathrm{C}++$ language which produced various types of visualization while using VTK. Visualization of pressure distributions and streamlines on the model surfaces are important for identification of aerodynamic problems and making corrections and modifications possible before the construction of the physical model. 


\section{Introdução.}

A Visualização, no seu sentido mais amplo, é desde muito tempo uma ferramenta muito utilizada pelo homem para facilitar o entendimento em todo tipo de problema. Antes do surgimento dos computadores os homens utilizavam o desenho como forma de diagramar as mais variadas questões. Mesmo com a precariedade destes desenhos, pois a quantidade de dados deveria ser pequena, eram muito úteis ao que se propunham, uma vez que a visão para o ser humano tem grande caráter intuitivo. Entretanto seria impossível a demonstração de enorme quantidade de dados, com bom entendimento, através de desenhos.

A Visualização Computacional definida como uma tradução de informações para um formato gráfico, é uma área que atualmente conta com uma grande contingência de pesquisadores do mundo todo. A razão para esse destaque e desenvolvimento é o desafio e a necessidade, uma vez que parece existir mais informação disponível para ser interpretada do que tempo hábil para fazê-lo. $\mathrm{O}$ aumento do poder computacional e conseqüente desenvolvimento das técnicas numéricas de simulação, aliados ao avanço tecnológico dos periféricos de medição, fizeram com que muitas áreas de pesquisa, passassem a necessitar de ferramentas gráficas e de auxilio computacional constante para apoiar o processo de interpretação das informações geradas. Recentemente a Visualização Computacional foi subdividida em Científica, de Informação e de Software. A Visualização Cientifica trabalha com dados científicos de diversas áreas como a Medicina, a Meteorologia, Dinâmica e Mecânica de Fluidos, Estudos dos Solos e muitos outros exemplos. Enquanto que a de Informação trata de Base de Dados, Web, Carga em Redes, Relações Humanas, etc. E a de Software trata de Projetos, Depuração, Testes, etc.

Inúmeras áreas têm se beneficiado dos produtos da Visualização, em particular a área científica. Merecem destaque o campo de Mecânica dos Fluidos, precursor do uso de Visualização na área cientifica devido aos resultados gerados por simulação numérica e, as aplicações envolvendo Imagens Médicas.

Profissionais de medicina constituem exemplos típicos de usuários de Visualização, consequiência do aumento dos periféricos de medição (como Tomografia Computadorizada, Ressonância Magnética, etc.). Muitas outras aplicações científicas e profissionais se beneficiam dos resultados da Visualização, como a biologia molecular, meteorologia, ciências ambientais, microscopia, odontologia, física nuclear, engenharia aeronáutica e automotiva, geologia e geografia. A aplicação de técnicas gráficas para ampliar a capacidade de interpretação de dados cientificas tem 
sido denominada internacionalmente Visualização em Computação Cientifica (ViSC Visualization in Scientific Computing).

A Mecânica dos Fluidos que estuda problemas físicos a respeito das relações entre os fluidos e o meio em que estão inseridos possuem implicações em problemas de projeto e análise na engenharia (aerodinâmica, termodinâmica, hidráulica, etc.). A complexidade real dos escoamentos de fluidos acabou de ser confirmada com a expressão completa das equações de movimento de Navier-Stokes, obtida na primeira metade do século XIX. Os grandes avanços da aeronáutica neste século passaram a impor novos desafios, com muitos problemas que demandariam soluções eficientes. Assim, várias formas de aproximação teórica tornaram-se úteis, mesmo que inexatas. O desenvolvimento de computadores digitais de alta velocidade abriu a possibilidade de solucionar as equações completas de movimento de um fluido através de métodos numéricos. No entanto, mesmo trabalhos recentes indicam que, para aplicações aerodinâmicas práticas as soluções das equações de Navier-Stokes impõem dificuldades de ordem prática. A elaboração de métodos numéricos intermediários, cuja capacidade se localiza entre a solução das equações completas de NavierStokes e as aproximações simplificadas atenderam à necessidade de soluções mais rápidas e eficientes. Esses métodos, embora ainda submetidos a hipóteses restritivas, aumentaram a generalidade das aplicações e a complementação dos métodos experimentais.

O Método dos Painéis é um dos primeiros desses métodos intermediários, que parte das hipóteses do escoamento potencial incompressível. Foi implementado e utilizado pela primeira vez em meados da década de 1950. Este tipo de método foi desenvolvido em diversas formas e utilizado com sucesso em inúmeras aplicações industriais e de pesquisa em aerodinâmica e aeronáutica. $\mathrm{O}$ Método dos Painéis possui a capacidade de prever velocidades e forças atuantes sobre corpos de geometria qualquer, imersos em escoamentos ideais (invíscidos e incompressíveis). Estas hipóteses podem ser bastante satisfatórias para vários tipos de escoamentos reais, para o quais o número de Reynolds esteja acima de um certo limite mínimo e as camadas-limite envolvidas não apresentem separação ou espessamento apreciável. Este tipo de condição é bastante frequiente em aplicações aeronáuticas, as quais muitas vezes também aceitam correções para efeitos de compressibilidade e viscosidade. Mesmo com o surgimento de métodos mais avançados, com hipóteses mais abrangentes, o baixo custo, a flexibilidade e a exatidão relativa dos métodos dos painéis os tornam a escolha mais adequada para muitas aplicações aeronáuticas, sob escoamentos subsônicos e subcríticos.

A análise dos escoamentos aerodinâmicos em aplicações aeroespaciais envolve a obtenção de quatro ou cinco variáveis independentes. No caso de simulações numéricas típicas, atualmente esses dados podem ser obtidos sobre uma quantidade de pontos da ordem de mais de um milhão. (DELMARCELLE \& HESSELINK, 1995). É evidente que a análise desses grandes conjuntos de dados vem exatamente de encontro às propostas da Visualização Científica (BRODLIE et al., 1992), ou seja, "tornar visível o invisível" de maneira a possibilitar o entendimento local ou global de um determinado fenômeno a partir de conjuntos de dados que o descrevam. A criação de mapeamentos/representações capazes de transmitir, dentro das limitações humanas, a maior quantidade de dados da melhor maneira possível é o objetivo principal da Visualização Cientifica.

O presente trabalho tem como principais objetivos o entendimento e a utilização do software de simulação numérica em método dos painéis, o Panflo 2.0 (comentado nos próximos 
capítulos e explicado no Apêndice A), criar uma Visualização Cientifica adequada para aplicar a modelos aerodinâmicos, promover a viabilidade de utilização desta ferramenta para o laboratório e por fim aplicar a simulação e o pós-processamento a dois modelos aerodinâmicos de pesquisa do laboratório. Para isso foram gerados os dados da geometria dos modelos em malhas simples de vértices que servem de entrada para o simulador, além dos dados de simulação, como velocidade, angulo de ataque, entre outros que o programa possui, ou seja, montar os arquivos $p f i$ e $p f g$ exemplificados no Apêndice B. Ao obter os resultados da simulação estes foram submetidos as rotinas criadas para visualização e em seguida preparados para a apresentação e análise. 


\section{Revisão Bibliográfica.}

\subsection{Método dos Painéis}

\subsubsection{Histórico: (Origem e evolução dos métodos de painéis)}

Os métodos de painéis tiveram seu surgimento em meados da década de 1950. O autor (KRAUS, 1978) foi um dos primeiros autores a estabelecer um discernimento entre os tipos de métodos de painéis até então existentes. Os autores (KATZ \& PLOTKIN, 1991) apresentam uma revisão histórica resumida, colocando os trabalhos de desenvolvimento de métodos de painéis numa seqüência cronológica, dividida em três gerações de desenvolvimento que teriam as seguintes principais características.

Primeira Geração: surgimento dos métodos de painéis. Propostas de métodos de ordem reduzida que se utilizam de painéis planos associados a distribuições constantes de singularidades. Maior utilização da condição de contorno de Neumann.

Segunda Geração: caracterizada por um aumento da sofisticação dos modelos empregados, com o surgimento de métodos de ordem elevada na busca por um suposto incremento de exatidão da solução. Utilização ampla de ambas as formas de condição de contorno (Neumann e Dirichlet).

Terceira Geração: caracterizada por um retorno às formas de modelagens mais simples, típicas da primeira geração. Aumento da utilização da condição de contorno de Dirichlet. Maior acesso aos métodos de painéis por parte de entidades e empresas menores, devido a maior disponibilidade de equipamento computacional de capacidade suficiente.

\subsubsection{Aspectos particulares aos métodos de painéis.}

Muitos desses aspectos são fonte de divergências entre os diversos autores revisados, gerando debates quanto à forma eventualmente mais adequada de tratá-los. Os assuntos variam desde a sofisticação necessária aos modelos utilizados na representação da geometria e 
singularidades (ordem de representação) até os méritos relativos entre as condições de contorno de Neumann e Dirichlet, chegando a pontos relativos à praticidade, tais como eficiência numérica e custo computacional.

Por se tratar de um método amplamente estudado, o presente capítulo se restringe a fazer uma breve introdução, utilizando-se da revisão bibliográfica feita sobre o assunto. Seguindo também o modelo utilizado na implementação do software de Método dos Painéis utilizado neste trabalho, o qual se restringe a métodos dos painéis para escoamentos tridimensionais, em regime de escoamento estacionário, subsônico e subcrítico, voltados para aplicações relacionadas à engenharia de mobilidade (aeronáutica, automobilística, etc.).

"Método de Painéis" é como são chamadas, genericamente, técnicas de análise numérica dos fluidos que obedecem a equação de Laplace e se encaixam na categoria chamada de métodos de contorno, (HESS, 1990), ou seja, tratam da consideração das condições de contorno, e que no caso específico desses métodos tratam das condições do escoamento de um fluido na superfície de um corpo sob análise, (dividida em elementos de área chamados de painéis), assim definindo as características do escoamento ao redor de um ou mais corpos, sob a hipótese de que o escoamento seja potencial.

$$
\nabla^{2} \phi=0
$$

A solução diferencial linear da equação de Laplace (1), permite obter $\phi$ e conseqüentemente o vetor velocidade em qualquer ponto do escoamento. Para resolver essa equação esses métodos se utilizam da representação do potencial por singularidades superficiais, usualmente na forma da seguinte equação:

$$
\phi(P)=\frac{1}{4 \pi} \iiint_{S I}\left[-\sigma\left(\frac{1}{r}\right)+\mu \nabla\left(\frac{1}{r}\right) \wedge n\right] d s+\mu p+\phi_{o o}
$$

Onde:

SI = superfície de integração onde:

$\mathrm{SI}=\mathrm{S}$, se $\mathrm{P}$ não pertence à superfície.

SI $=$ S-P $($ S excluindo-se $P)$, se $P$ pertence a superfície.

$\mu p \quad=0$, se $\mathrm{P}$ não pertence a superfície.

$\mu \quad=(\phi(P)-\phi i(P)) / 2=\mu(P) / 2$, se P pertence a superfície.

$\mathrm{S}=$ área superficial do corpo.

VISUALIZAÇÃO CIENTIFICA COMPUTACIONAL APLICADA A MODELOS AERODINÂMICOS SIMULADOS EM MÉTODO DOS PAINEIS. 
$r=$ distância de $\mathrm{P}$ a um ponto centrado no elemento dS.

Uma das características mais importantes da equação (2) é o fato de que as incógnitas $\sigma$ e $\mu$ (singularidades de dipolos) são associadas apenas à superfície do corpo, assim qualquer método de solução para esses valores deverá atuar apenas sobre essa superfície, não sendo necessário resolver o valor de $\phi$ em todo o campo do escoamento o que significa uma grande redução em trabalho computacional.

Soluções para as distribuições de intensidades de singularidades $\sigma$ e $\mu$ sob a condição de contorno de velocidade normal a superfície, não podem ser obtidas em forma analítica fechada, a não ser para alguns casos de geometria simples.

Em um método de painéis, a geometria da superfície do corpo e as funções de distribuição de singularidades são discretizadas. Para isso, a superfície do corpo é aproximada, por elementos que a subdividem. A geometria de cada elemento é descrita por uma função aproximada com base nos pontos conhecidos da superfície do corpo. Sobre a superfície de cada elemento, as distribuições de singularidades são aproximadas por funções de forma determinada onde as intensidades locais são expressas como uma combinação linear de um certo número de parâmetros.

A descrição de um método de ordem reduzida, ou seja, que utiliza representações mais simplificadas em sua geometria, é apresentada a seguir em etapas básicas presentes em qualquer método de painéis.

1. A superfície do corpo é aproximada por elementos quadrilaterais, ou painéis. Os quatro vértices de cada painel são pontos pertencentes a superfície.

2. Sobre cada painel assume-se que as singularidades são distribuídas com intensidades $\sigma$ ou $\mu$ sobre a superfície.

O procedimento usual para este tipo de método é selecionar um ponto da superfície de cada painel como ponto de controle. Normalmente o ponto selecionado é aproximado como sendo o centróide dos outros cantos de cada painel. O versor normal n é aproximado pelo versor na direção do produto vetorial entre os vetores diagonais do painel.

$\hat{n}=(B D x A C) /|B D x A C| \quad p c=$ ponto de controle: centróide de $\mathrm{ABCD}$. 


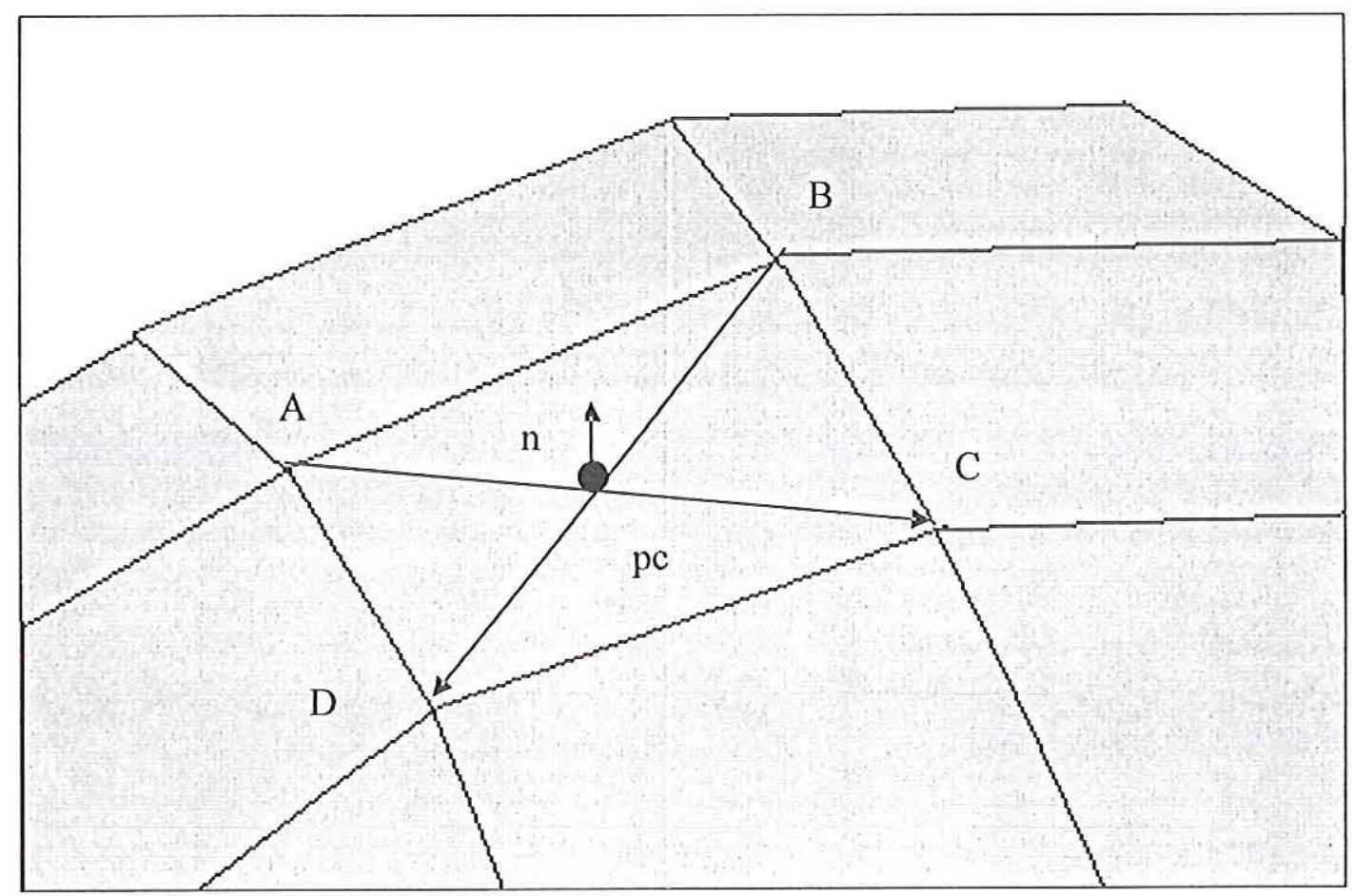

FIGURA 2.1.2.1. - Ponto de controle e versor normal sobre um painel quadrilateral.

De posse das velocidades locais, pressões podem ser calculadas a partir da equação de Bernoulli. Usualmente, as pressões locais p são expressas em termos de sua diferença em relação à pressão do escoamento livre, p po, através do coeficiente adimensional de pressão Cp:

$$
C p=\frac{p-p \infty}{\frac{1}{2} \rho U_{\infty}^{2}}=1-\left(\frac{\|V i-U \infty\|}{U \infty}\right)^{2}
$$

As forças resultantes sobre o corpo podem ser calculadas por integração numérica dessas pressões na superfície, ou por avaliação das velocidades induzidas pelo corpo nas faces de um volume de controle que o envolve.

Quanto à questão do tipo de combinação de singularidades devem ser relativos ao tipo de aplicação desejada para o método, além disso, leva-se em conta o melhor condicionamento numérico que uma combinação de singularidades pode proporcionar a essa aplicação. 


\subsubsection{Aplicação de método de painéis em configurações aeronáuticas.}

Em aerodinâmica aeronáutica o principal interesse está relacionado não apenas ao comportamento do escoamento ao redor dos corpos, mas também as forças resultantes que estes corpos sofrem, as quais geralmente definem a eficiência aerodinâmica de uma aeronave.

Com o conceito de camada limite, a viscosidade de um fluido possibilita que camadas adjacentes de fluido, definidas por superfícies de corrente, troquem quantidade de movimento por difusão. Sobre superfícies sólidas, é possível constatar experimentalmente que a velocidade tangencial é nula. Combinando-se os dois efeitos, a presença da fronteira sólida promove uma redução da quantidade de movimento do fluido em uma região próxima, à medida que o fluido se movimenta ao redor da superfície. Em muitos escoamentos este efeito limita-se a uma região bem definida, a camada limite, sendo que na região externa a essa camada o escoamento não sofre efeitos apreciáveis da viscosidade e pode ter seu movimento descrito pelas equações de Euler.

A taxa de deformação do fluido associada à camada limite correspondente a uma tensão tangencial aplicada a superfície, que resulta em uma força de arrasto, no sentido do escoamento livre, aplicada sobre o corpo. A medida em que se desenvolve, a camada limite pode também sofrer separação sob gradientes adversos de pressão, o que promove regiões turbulentas de grande perda de energia e baixa pressão, que contribuem para o aumento dessa força de arrasto.

O gradiente de velocidades característico da camada limite introduz vorticidade no escoamento, tornando possível a existência de circulação não nula ao redor dos corpos envolvidos.

Observa-se experimentalmente que, para corpos com certas geometrias particulares, tais como os aerofólios de superfícies sustentadoras de aeronaves (asas, estabilizadores e auxiliares), essa vorticidade pode induzir a condição de Kutta. Sob essa condição o escoamento, quando não separado, flui continuamente a partir do bordo de fuga agudo do aerofólio introduzindo circulação no escoamento.

Segundo a lei de Kutta-Joukowski (KATZ \& PLOTKIN, 1991), a circulação provoca uma taxa de variação de quantidade de movimento na direção transversal ao escoamento livre, que se reflete em uma força resultante aplicada sobre o corpo nesta direção. Esta força é usualmente chamada de sustentação, e constitui a base da capacidade de vôo na maioria das aeronaves utilizadas hoje.

Portanto, num escoamento subcrítico, quaisquer forças sofridas por um corpo serão sempre causadas pelos efeitos da viscosidade do fluido em consequiência da vorticidade do campo de velocidades a ela associada. No entanto, uma das hipóteses para a representação potencial do escoamento consiste justamente na suposição de um fluido invíscido, ou seja, incapaz de gerar vorticidade.

Para auxiliar na determinação das características aerodinâmicas de novas aeronaves ou de modificações de outras já existentes. As aplicações mais freqüentes são:

- Análise comparativa entre diferentes configurações de aeronaves.

VISUALIZAÇÃO CIENTIFICA COMPUTACIONAL APLICADA A MODELOS AERODINÂMICOS SIMULADOS EM MÉTODO DOS PAINEIS. 
- Predição de forças de sustentação e arrasto induzido, com métodos acoplados a representações de camada limite ou não.

- $\quad$ Predição de características de estabilidade longitudinal de aeronaves e suas variações devido a alterações geométricas em superfícies auxiliares (estabilizadores e outros).

- Avaliação qualitativa de distribuição de pressão e velocidades e sua alteração devido a modificações geométricas. Localização de características inadequadas, permitindo sua correção.

- Predição de distribuições de sustentação sobre asas, necessárias para estimar as cargas estruturais a serem resistidas.

- Interferência de esteiras de vorticidade e as partes de aeronaves, através de métodos de precisão da geometria dessas esteiras.

- Auxilio na integração aerodinâmica de sistemas em aeronaves de transporte, buscando reduzir perdas de energia.

- Predição de características gerais de configurações para sustentação elevada, envolvendo flapes e outras estruturas geometricamente complexas.

Tendo em vista as limitações impostas pelo escoamento potencial incompressível, ainda assim os métodos de painéis encontraram aceitação para uma gama tão diversa de utilizações devido às várias condições e características citadas a seguir:

- $\quad$ Os métodos de painéis possuem boa capacidade de previsão de forças de sustentação e arrasto induzido para pequenos ângulos de ataque.

- Muitos resultados podem tornar-se satisfatórios com correções adequadas, tais como modelo de camada limite e métodos para a determinação da forma de esteiras.

- Em muitas aplicações práticas, não se espera exatidão absoluta de resultados uma vez que os métodos são utilizados em combinação a outras técnicas, tais como testes experimentais. A utilização de vários tipos de métodos permite a compensação das deficiências de cada um.

- Na maioria dos casos, a condição idealizada representada pelo escoamento potencial também representa uma máxima eficiência teórica que seria atingida para Re $\rightarrow \infty$. Desta maneira, muitos resultados definem limites para as possíveis características do escoamento real, garantindo que este "nunca será melhor" que o resultado ideal.

- Apesar de suas capacidades limitadas em muitas situações os métodos de painéis podem ser mais exatos dentro de suas próprias hipóteses do que outros métodos com hipóteses mais abrangentes, como por exemplo, soluções numéricas das equações de Euler e Navier-Stokes. Dessa maneira, é possível afirmar que os métodos de painéis são relativamente mais exatos, gerando confiabilidade em seus resultados.

- A confiabilidade dos métodos de painéis, ainda que dentro de suas hipóteses, garante estudos comparativos concisos. Por exemplo: se dois casos de geometrias diferentes devem ser comparados, existe grande probabilidade de que as diferenças nos 
resultados refletirão as diferenças geométricas entre os casos, com os níveis relativos de importância física (aerodinâmica) de cada um devidamente representada.

- As hipóteses básicas dos métodos de painéis em geral não pressupõem quaisquer restrições quanto à geometria que pode ser analisada, o que não é o caso de outros métodos com hipóteses de escoamento mais abrangentes.

- Em muitas aplicações práticas, o discernimento e a experiência do analista no julgamento do resultado tem importante papel, definindo que valores podem ser úteis ou não. Este fato pode tornar úteis resultados que, a rigor, não reproduzem a realidade.

- Em termos de utilização prática, a maioria dos autores afirma que as maiores vantagens dos métodos de painéis são:

1. Custo computacional mais baixo que outros métodos de hipóteses mais abrangentes

2. Maior facilidade na preparação da discretização geométrica, uma vez que não é necessário gerar uma complexa malha volumétrica.

3. Uma absoluta generalidade muito abrangente quanto à geometria que pode ser analisada, por ser um método potencial.

Uma revisão completa e bem discutida sobre Método dos Painéis pode ser encontrada em (MARTINS, 1997). 


\section{Visualização Computacional}

A visualização, como é chamada, consiste em uma "tradução" de dados e informações para um formato gráfico e é considerada essencial para se utilizar o grande potencial humano em visualizar.

Para o termo Visualização já existem várias definições. Em seu sentido mais amplo, podese dizer que Visualização significa uma geração de imagens para a organização e entendimento de um conceito idéia ou informação.

Recentemente a área de Visualização foi subdividida, conforme a classe de aplicações para qual uma técnica especifica é utilizada, em três sub-áreas. Dentre elas a chamada Visualização Cientifica que tem como definição típica a seguinte citação: "Visualização é mais do que um método de computação. Visualização é o processo de transformar informação para uma forma visual, permitindo aos usuários observar a informação. A apresentação visual resultante permite ao cientista ou engenheiro perceber visualmente características que estão escondidas nos dados, mas que são necessárias para tarefas de exploração e análise”. (GERSHON, 1994) 
A figura 3.1. a seguir ilustra dois exemplos de visualizações cientificas.

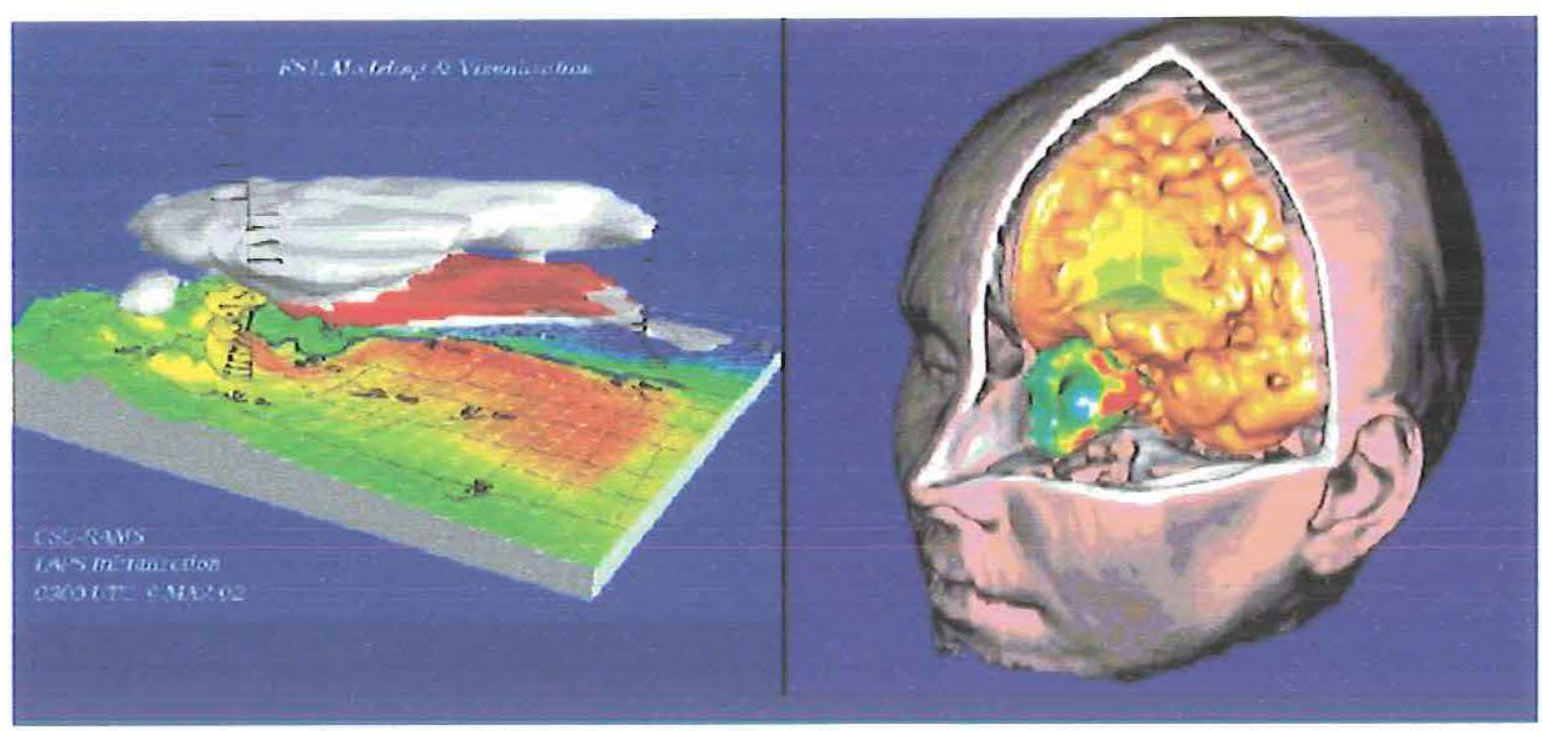

FIGURA 3.1. - Exemplo de aplicações (à esquerda, em meteorologia; à direita, em medicina)

Em qualquer sub-área a Visualização é baseada na utilização de algoritmos e bibliotecas de Computação Gráfica, assim, alguns conceitos de CG devem ser brevemente citados:

A chamada renderização é o que se pode definir como um processo de geração de uma imagem em uma tela a partir de um algoritmo ou descrição computacional qualquer. Essa renderização gera a imagem de um objeto simulando seu ambiente, sua iluminação e uma fonte de observação. Para se apresentar objetos (rendering) em computação grafica é necessário definir uma cena que é o ambiente, objetos chamados atores, uma fonte de observação chamada câmera, uma fonte de luz, entre outras coisas. Para facilitar o processo de iluminação e cor, que é chamado de tonalização (shading) existem modelos de cores como o RGB (Red, Green, Blue) e o HSV (Hue, Saturation, Value, ou Matiz, Saturação, Brilho).

A Visualização Cientifica ou ViSC (Visualization in Scientific Computing) tem como objetivos estudar formas e algoritmos para mapear informações numéricas em representações gráficas, não se propondo a entender os dados por si só mas sim o fenômeno que os gerou.

Uma técnica de Visualização envolve vários passos: a construção de um modelo empírico a partir dos dados; a seleção de algum mecanismo de mapeamento do modelo em um objeto de visualização abstrato, como uma imagem ou um mapa de contornos; e a renderização da imagem no dispositivo de exibição gráfico. 
Em ViSC, os dados podem estar definidos sobre domínios bidimensionais (2D), tridimensionais (3D) e, genericamente, multidimensionais. Em geral estão organizados em uma malha (regular ou irregular), mas podem se constituir de um conjunto de pontos esparsos. As informações associadas a cada ponto podem ser um ou mais valores escalares, e os dados podem ser estáticos ou variantes no tempo. Os dados em si podem ser de natureza escalar (números que indicam temperatura, pressão, umidade, etc), vetorial (vetores que indicam velocidade, campo elétrico, etc.) ou tensoriais (tensores que indicam fadiga de um material, etc). No caso de dados vetoriais, uma técnica natural é a utilização de setas, ou seja, segmentos de retas orientados para representar visualmente cada vetor ( $g l y p h s$ ). Outro exemplo de técnica para visualização de dados vetoriais é a de streamlines, construídas escolhendo-se um ponto inicial de onde partem os segmentos de reta que descrevem de forma aproximada a trajetória de partículas no fluxo.

Os sistemas de visualização devem ser usados como parte integrante do processo de investigação cientifica. Ao investigar um fenômeno se está, normalmente, tentando encontrar um modelo que explique os dados empíricos obtidos do "mundo real".

No ciclo de investigação, o cientista usa o seu discernimento e conhecimento sobre o fenômeno para formular uma hipótese, coletar dados, controlar um processo de computação, visualizar e interpretar os resultados e, em seguida, repetir e refinar o ciclo.

\subsection{Visualização Cientifica em Mecânica dos Fluidos.}

Os estudos em Mecânica dos Fluidos sempre envolvem a observação de inúmeras variáveis em espaços multidimensionais contínuos e, portanto apresentam o potencial de gerar grandes conjuntos de dados multivariados os quais, podem gerar problemas complexos de visualização.

A grande fonte de dados relativos a análises de problemas fluídicos tem sido a disponibilidade crescente de potência computacional suficiente para a solução numérica das equações de movimento/estado que descrevem o comportamento de fluidos. Antes do advento computacional, a solução destes sistemas de equações diferenciais parciais não lineares era praticamente impossível. Como exemplo da complexidade dos dados envolvidos, pode-se citar a análise do escoamento aerodinâmico em aplicações aeroespaciais, que tipicamente envolve a obtenção de quatro a cinco variáveis escalares/vetoriais independentes. 
No caso de simulações numéricas típicas, atualmente estes dados podem ser obtidos sobre uma quantidade de pontos da ordem de mais de um millão (DELMARCELLE \& HESSELINK, 1995).

É evidente que a análise destes grandes conjuntos de dados vem exatamente de encontro às propostas da Visualização Cientifica enquanto disciplina (BRODILIE et al., 1992), ou seja, "tornar visível o invisível" de maneira a possibilitar o entendimento local ou global de um determinado fenômeno a partir de conjuntos de dados que o descrevam. A criação de mapeamento/representações capazes de transmitir, dentro das limitações humanas, a maior quantidade de dados da mellor maneira possível é um dos objetivos da Visualização Cientifica.

Aplicações de Visualização em Fluidos segundo a bibliografia (DELMARCELLE \& HESSELINK, 1995) onde os autores identificam três principais campos de aplicação das representações, considerados indispensáveis:

- Aumento do conhecimento do processo físico: obviamente, a possibilidade de visualizar o fenômeno de diferentes maneiras permite um maior discernimento dos fatores envolvidos e suas relações. Além disso, no caso de CFD, certas grandezas que não são visualizáveis experimentalmente (tais como tensões ou vorticidade) podem ser incluídas no modelo visual e associadas a características gráficas.

- Refinamento de métodos computacionais e/ou experimentais tanto em procedimentos experimentais quanto de simulação computacional (CFD), a visualização de resultados intermediários permite descobrir eventuais discrepâncias dos modelos ou métodos adotados, que podem ser corrigidas numa re-execução dos procedimentos, num processo interativo de refinamento.

- Validação de métodos computacionais: estes podem ser validados através da visualização comparativa com outros métodos e resultados experimentais. Esta explicação é diretamente relacionada, por exemplo, à validação de modelos de turbulência adotados em CFD.

\subsubsection{Visualização de Campos Escalares.}

Dados escalares como, densidade, pressão, temperatura e entalpia, são visualizados em Mecânica dos Fluidos, de forma similar as demais aplicações que envolvem este tipo de 
informações. As técnicas principais envolvem traçado de contorno em 2D e de superfícies de nível em 3D. A primeira delas permite identificar valores de interesse em visualizações bidimensionais e a segunda apóia a descrição do comportamento de valores de interesse num volume, para imagens estáticas.

Dados escalares bidimensionais podem ser visualizados de diversas formas, dentre elas traçados de contornos (isolinhas), sombreamento discreto, mapeamento por cores e visualização superficial. Algumas destas técnicas se prestam a visualização de mais de dois escalares ao mesmo tempo. Dados escalares tridimensionais são usualmente visualizados através de superfícies de nível (isosurfaces). Conjuntos de dados escalares volumétricos podem ser considerados de dimensão $4 \mathrm{e}$ representados por uma função de três variáveis:

$w=f(x, y, z)$

Onde $\mathrm{x}, \mathrm{y}$ e $\mathrm{z}$ são as coordenadas dos pontos no espaço 3D e w é o valor simulado (ou amostrado) naquele ponto.

A criação de superfícies de nível envolve a execução de um processo para mapear este conjunto $4 \mathrm{D}$, visualizando o comportamento do dado em certas regiões ou valores críticos e plotando a superfície dada por:

$k=f(x, y, z)$

Onde k (constante) é o valor sob análise.

Algumas vantagens das isosurfaces incluem a possibilidade de observação de estrutura nas medições ou simulações, além de permitir a geração e análise em tempo real na maioria do hardware disponível para geração de imagens. Com o uso de isosurfaces, entretanto, perde-se a informação do conteúdo do conjunto de dados fora dos valores de interesse.

\subsubsection{Representação de Campos Vetoriais}

As representações elementares são: 
- Ícones Puntuais - consiste em atribuir um segmento de reta orientado ao ponto em questão, com direção e sentido do vetor e, em geral, o comprimento proporcional a magnitude do vetor. Uma técnica análoga à colocação de tufts.

- Linhas de Escoamento - Representações que envolvem linhas atravessando o domínio são mais abrangentes, uma vez que implicam numa interpolação dos valores envolvidos. Para campos vetoriais em escoamento de fluidos, tem-se casos específicos como trajetórias (particle traces), linhas de emissão (streaklines) e linhas de corrente (streamlines).

- Superfícies de Escoamento (streamsurfaces) - Para cada linha de escoamento temos um ponto de origem $\mathrm{x}_{0}$, uma superfície de escoamento seria gerada ao traçarmos as linhas de escoamento para cada um dos infinitos pontos de um segmento de linha de origem, ou seja, um conjunto contínuo de pontos de origem $\mathrm{x}_{0}$. O equivalente experimental para um campo de velocidades seria a emissão de várias partículas adjacentes numa mesma linha simultaneamente, que seriam conveccionadas pelo escoamento, desenvolvendo uma superfície.

Os autores defendem que o realismo da imagem final é uma das características mais importantes para facilitar a visualização qualitativa de escoamentos de fluidos, enfatizando que os pacotes para visualização de fluidos atualmente disponíveis não empregam os devidos recursos e destacam a variação de detalhes que possibilitam o ajuste de parâmetros de renderização e iluminação.

Os modelos de iluminação são baseados no conceito de Blinn/Kajiya, descrito em detalhe em (WATT,A. \& WATT, M., 1992), que inclui, em geral, contribuições da densidade do meio, reflexividade do material e as posições das fontes de luz e do observador. Os métodos apresentados em ordem de complexidade são:

- Renderização básica com modelo básico de iluminação, adequado para "previews" e elaboração de animações.

- Renderização com modelo simplificado de iluminação, porém com maior flexibilidade das funções transferência de cor e opacidade empregadas, possibilitando a elaboração de "máscaras" para realçar ou isolar regiões de interesse do domínio.

- Renderização com modelo complexo de iluminação, para obtenção de maior realismo. 
Por um lado o realismo é um fator desejável na visualização em Mecânica dos Fluidos para uma validação qualitativa com resultados experimentais, mas sem esquecer de um dos principais objetivos da Visualização Cientifica que é "superar as limitações da observação experimental" e que para alcançar esse objetivo é imprescindível à geração de representações abstratas, e não apenas de simulações realísticas.

\subsubsection{Representações Vetoriais Locais}

Representações locais são aquelas que transmitem informação sobre os pontos do domínio que ocupam e sobre pontos numa região adjacente. Os autores (DELMARCELLE \& HESSELINK, 1995) introduzem a abordagem e representações locais para campos vetoriais em fluidos com o conceito de pontos críticos. Estes são pontos que correspondem a singularidades na solução das equações diferenciais parciais que regem o escoamento de fluidos, nas quais a magnitude do campo é nula e as declividades das linhas de corrente que ali convergem são indeterminadas. Geralmente, correspondem a pontos do escoamento nos quais importantes características do comportamento do fluido são definidas, tais como separação da camada limite, pontos/regiões de adesão, bolhas de separação, centros de vórtices, etc.

Em escoamentos bidimensionais, os pontos críticos se dividem em seis tipos básicos, cada qual com seu padrão característico do campo vetorial adjacente. Em três dimensões, os possíveis campos adjacentes aos pontos críticos correspondem a combinações dos seis tipos de campos bidimensionais, definidos em três planos perpendiculares e intersectantes no ponto critico.

Outras representações locais apresentadas por (DELMARCELLE \& HESSELINK, 1995) são os conceitos de "streamribbons" (faixas de escoamento) e "streamtubes" (tubos de escoamento); ambas são capazes de transmitir a configuração local do escoamento/campo vetorial ao redor e ao longo de linhas de escoamento.

\subsubsection{Representações Vetoriais Globais}

Um campo vetorial de um escoamento não pode ser visualizado como um todo apenas acrescentando-se grandes quantidades de representações elementares e locais em muitos pontos do domínio, devido ao inevitável congestionamento visual decorrente. Além disso, o reconhecimento 
de características importantes passaria a depender dos pontos escolhidos para introduzir as representações; no caso geral, muitas destas características poderiam ser perdidas durante a análise dos dados visualizados, levando a conclusões errôneas, principalmente para escoamentos complexos. Conforme (DELMARCELLE \& HESSELINK, 1995), existe a necessidade evidente de maior abstração na representação: as características chave do escoamento devem ser localizadas por algum algoritmo e então representadas simplificadamente, porém de uma forma que o comportamento geral do campo vetorial possa ser intuído a partir da visualização.

Os autores (HELMAN \& HESSELINK, 1991) propuseram a extração da topologia do campo vetorial, a qual seria definida localizando-se dois tipos de características chave: os pontos críticos do campo e as linhas ou superfícies de corrente que os interligam, num dado instante do tempo; esse conjunto corresponde a topologia da solução das equações diferenciais parciais que regem o escoamento. Todo campo vetorial pode ser intuído a partir desta topologia, pois se sabe que o campo é tangente as linhas/superfícies de corrente e o comportamento geral do campo na região dos pontos críticos também é conhecido. Uma vez definida a "malha" de interligações entre os pontos e as linhas, todo o problema é contornado com poucas entidades geométricas.

Em sua obra (DELMARCELLE \& HESSELINK, 1995) citam ainda duas outras representações globais para campos vetoriais. A primeira seria a chamada contração dos dados, feita obtendo-se do campo vetorial uma grandeza escalar de interesse. A Outra técnica sugerida é a detecção de linhas centrais de vórtices ("vortex cores"). As linhas centrais são linhas de escoamento em torno das quais se desenvolvem vórtices, que são entidades determinantes do escoamento como um todo.

Segundo as conclusões dos autores em (MARTINS, 1997), as representações elementares locais são tão importantes quanto as globais. Não se trata apenas da maior ou menor eficiência na transmissão de informação, mas sim da necessidade de que a análise cientifica passe por uma seqüência completa de etapas, partindo de representações elementares; estas, devido a sua semelhança com técnicas experimentais e simplicidade inerente, fornecem noções intuitivas subjetivas que são imprescindíveis para fornecer ao analista um embasamento adequado a geração e compreensão de representações mais abstratas e práticas. Outro papel importante das técnicas de representação elementar é a possibilidade de gerar visualizações de resultados de análise numérica (CFD) com características semelhantes a resultados experimentais. Esse procedimento pode constituir um passo inicial de validação qualitativa dos resultados numéricos, o qual permite definir premissas para guiar e poupar esforços numa posterior validação quantitativa. Outro mérito 
importante de muitas representações elementares é seu baixo custo de obtenção e a possibilidade de interação com o usuário analista através de animação e/ou dispositivos virtuais.

Para aplicações aeroespaciais, existe uma defasagem/atraso considerável entre a criação de novas técnicas de visualização úteis e sua utilização em pesquisa nessa área. Técnicas mais antigas, tais como glyphs de vetores e linhas/superfícies de contorno, ainda predominam nos trabalhos de visualização de fluidos com aplicações aerodinâmicas. Em muitos casos, a aplicação simultânea de técnicas mais modernas poderia trazer esclarecimentos e "insight" maiores. Em resumo: aparentemente, ocorre resistência considerável a aplicação de novas técnicas, sendo a visualização de dados geralmente tratada em segundo plano. Os autores declaram acreditar que um maior contato deveria ser estabelecido entre o meio da Visualização Cientifica e muitos de seus usuários em Mecânica dos Fluidos.

\subsection{Visualização de Fluidos em Aerodinâmica.}

O principal objetivo da mecânica dos fluidos aplicada ao projeto de veículos consiste na obtenção de pressões superficiais atuantes na superfície de um corpo devido a sua interação com fluido em movimento. A distribuição de pressões superficiais determina as resultantes de força e momento sofridas pelo sistema, definindo seu comportamento dinâmico e eficiência energética como veículo (consumo de combustível). Além disso, refletem fenômenos importantes do campo completo de escoamento que podem ser controlados pelas características geométricas do sistema.

Distribuiçôes de pressão superficial são resultados típicos de ensaios experimentais em túneis de vento. Além disso, no inicio dos anos 70 tornaram-se disponíveis os primeiros métodos viáveis de simulação numérica aplicáveis a escoamentos aerodinâmicos ao redor de geometrias tridimensionais complexas, referidos de forma genérica como métodos de painéis. Hoje, existem métodos de simulação numérica cada vez mais abrangentes que necessitam de uma ferramenta, tão poderosa quanto sua capacidade, para a visualização de seus resultados. 


\section{VTK - Visualization Tool Kit.}

É um modelo de software multiplataforma de baixo custo, que está adquirindo aceitação nas universidades e empresas do mundo todo. O software consiste em uma biblioteca de algoritmos e estruturas de dados para visualização compatível com plataformas UNIX, Windows NT e Windows. O VTK foi desenvolvido em C++ segundo a metodologia de orientação a objetos e é extensível, permitindo o desenvolvimento de novas aplicações com uma interface gráfica própria, a alteração das técnicas já implementadas e a inclusão de novas técnicas de visualização, pois o código fonte está disponível. Embora a definição de open source, como é chamado, seja discutível, a premissa básica é que o código fonte é livremente disponível para qualquer um que o queira. $\mathrm{A}$ disponibilidade do código fonte para muitas pessoas cria muitas oportunidades e vantagens no processo de desenvolvimento de software.

Recentemente, vários projetos de alto perfil têm encontrado soluções para atender o publico em geral. Dentre estes projetos inclui-se o sistema operacional LINUX, o Apache o Web Server e outros. Embora pessoas compartilhem códigos fontes desde o inicio dos computadores, novos modelos de negócios, o desenvolvimento de ferramentas e a internet permitiram a pratica de uma grande expansão deste tipo de atividade nos últimos 5 anos.

Os métodos implementados no VTK abrangem um conjunto relativamente grande de técnicas de visualização, e não são voltados para nenhum domínio de aplicação especifico, pois um dos objetivos dos desenvolvedores foi o de manter a generalidade do sistema. Dessa forma, o ambiente é extensível e relativamente fácil de usar por um usuário com conhecimentos de programação e algum domínio inicial de técnicas de visualização, oferecendo uma plataforma bastante adequada para a implementação de tarefas de visualização. Uma limitação, entretanto, é que o custo da generalidade do VTK é a perda de eficiência: é possível gerar boas visualizações a um custo relativamente alto em termos de tempo de processamento e ocupação de memória, pois nem algoritmos nem estruturas de dados estão otimizados para explorar aspectos específicos de uma 
aplicação. Ainda assim, o sistema oferece uma plataforma valiosa - e de baixo custo - para usuários de visualização experimentarem com as técnicas existentes.

O VTK oferece uma biblioteca de rotinas que executam funções gráficas $3 \mathrm{D}$ e de visualização. $\mathrm{O}$ ambiente, como já foi dito, foi projetado segundo a metodologia orientada a objetos, e escrito em $\mathrm{C}++$, podendo ser programado em $\mathrm{C}++$ e $\mathrm{Tcl} / \mathrm{Tk}$. Uma camada de código cria uma interface entre as funções do VTK e, no caso deste trabalho, $\mathrm{C}++$. Dessa forma, todas as funções do VTK estão disponíveis.

Para criar uma representação gráfica de um conjunto de dados, um programa deve possuir dois pipelines. Um de visualização, que transforma os dados originais (escalares, vetores ou tensores) em uma representação visual, e outro de renderização, que exibe a representação gráfica em tela, segundo atributos visuais selecionados pelo programador. A criação da visualização requer a conexão de módulos que manipulam e transformam os dados originais em uma representação gráfica (rede de visualização). Existem, basicamente, dois tipos de objetos:

Objetos de dados: são objetos que implementam os tipos de dados: Grids (malhas), valores, vetores, tensores, metadados (como fontes de luz, dimensões, transformações) e muitos outros. Como exemplo tem-se vtkStructuredPoints, que gerencia uma malha cartesiana, e o vtkPolyData, que manipula uma malha poligonal.

Objetos de Processo: são objetos que executam a criação e a transformação de dados. Exemplos são o vtkContourFilter, que gera linhas de altura em conjuntos 2D e superfícies de nível em conjuntos de dados 3D, e o vtkGlyph3D, que gera uma representação iconográfica de uma malha de dados vetoriais. Esses objetos geram dados (fontes - sources), transformam e manipulam esses dados (filtros - filters), ou gravam informação em arquivos (writers).

O último tipo de módulo a ser conectado ao pipeline de visualização é um mapeador (mapper), que é o inicio do pipeline de renderização, e que transforma a representação visual gerada em primitivas compatíveis com a biblioteca gráfica em uso.

Conexões em programas VTK se fazem através de comandos que unem saídas de um objeto a entradas de outros. Cada possível saída de um objeto pode ser ligada a entrada de vários outros, como se seu resultado pudesse ser visto por quaisquer objetos. Tal conexão, entretanto, só pode ser feita se a saída de um objeto e a entrada do objeto destino forem de tipos compatíveis. Por exemplo, um objeto que retorna em sua saída um conjunto de dados do tipo vtkStructuredPoints só pode ser conectado a objetos cuja entrada é, também do tipo vtkStruturedPoints, ou de uma superclasse dessa classe. 
O VTK permite a conexão de vários tipos de dados, incluindo modelos poligonais (vtkPolyData), que podem representar malhas planares irregulares, malhas cartezianas (vtksStructuredPoints), malhas regulares (vtkStructuredGrid) e malhas irregulares com células 3D (vtkUnstructuredGrid). Em VTK, as malhas são compostas por células, ou seja, os dados (escalares, vetores ou tensores) são armazenados nos vértices da estrutura. Possui também um formato de arquivo próprio de armazenamento de dados. Cada arquivo armazena um único objeto (ou malha) e seus dados, além de um número variado de tabelas de cores.

Após a definição do pipeline de visualização, uma cena deve ser criada, o que corresponde ao inicio do pipeline de renderização. Ou seja, a partir dos objetos gerados e mapeados, deve-se determinar o layout para a renderização. Isso é feito estabelecendo objetos do tipo atores, que são então colocados em cena. Esses atores são associados a mapeadores. Um mesmo mapeador pode ser associado a vários atores, de forma que o objeto a que ele corresponde pode aparecer diversas vezes na mesma cena ou em cenas diferentes, apresentando propriedades visuais (cor, posição, dimensão, etc.) variadas.

De uma maneira geral, os passos para visualizar uma cena são:

1. Criar os dados a serem visualizados

2. Filtrar os dados para técnicas desejadas

3. Criar uma janela de rendering

4. Criar um renderer

5. Mapear os dados para o sistema de rendering (biblioteca gráfica)

6. Renderizar a cena

7. Opcionalmente, criar um interactor (objeto responsável por manipulação interativa do resultado).

Os objetos básicos do VTK encarregados de realizar a renderização são:

vtkRenderWindow: gerencia uma janela no periférico de apresentação.

vtkRenderer: é o renderizador. Coordena o processo de renderização envolvendo luzes, câmeras e atores. 
vtkLight: define uma fonte de luz para iluminar a cena.

vtkCamera: define uma posição de observação e outras propriedades visuais da cena.

vtkActor: representa um objeto renderizado numa cena.

vtkProperty: define as propriedades de aparência de um ator, incluindo cor, transparência, e coeficientes de iluminação especular e difusa.

vtkMapper: a representação geométrica de um ator. Vários atores podem refereciar o mesmo mapper.

Existem aplicações em medicina (dados escalares de tomografia, ressonância magnética, e outros modos de captura para diagnóstico), em odontologia (reconstrução de dentes e arcadas para estudo), em dinâmica dos fluidos (visualização de movimento, velocidade, pressão, temperatura de gases, liquido, etc.), em biologia molecular, topografia, meteorologia, e outras áreas.

Para cada uma dessas áreas existem sistemas dedicados, e também sistemas de propósito geral, que podem ser adaptados e modificados para acomodar necessidades específicas de cada aplicação. Nestes casos, é essencial a interação entre profissionais da área gráfica e da área de aplicação.

No entanto, muitos problemas importantes ainda estão por ser resolvidos. Do ponto de vista dos conjuntos de dados, são necessárias estratégias para manipular conjuntos de dados cada vez maiores, já atingindo a dimensão de terabytes. Do ponto de vista de técnicas, é preciso desenvolver estratégias adequadas e efetivas para a visualização de informações altamente complexas e de natureza variada.

As figuras a seguir ilustram alguns exemplos de aplicações em VTK. A figura 4.1. se trata de aplicações médicas. A figura 4.2. é um projeto para a pesquisa com animais. A figura 4.3. é um trabalho de informação sobre mapas e solos. 


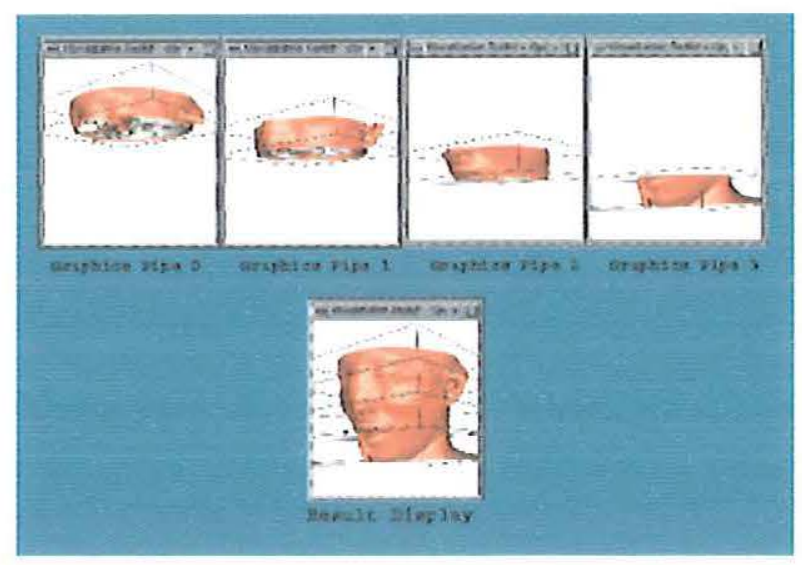

FIGURA 4.1. - Los Alamos National Lab

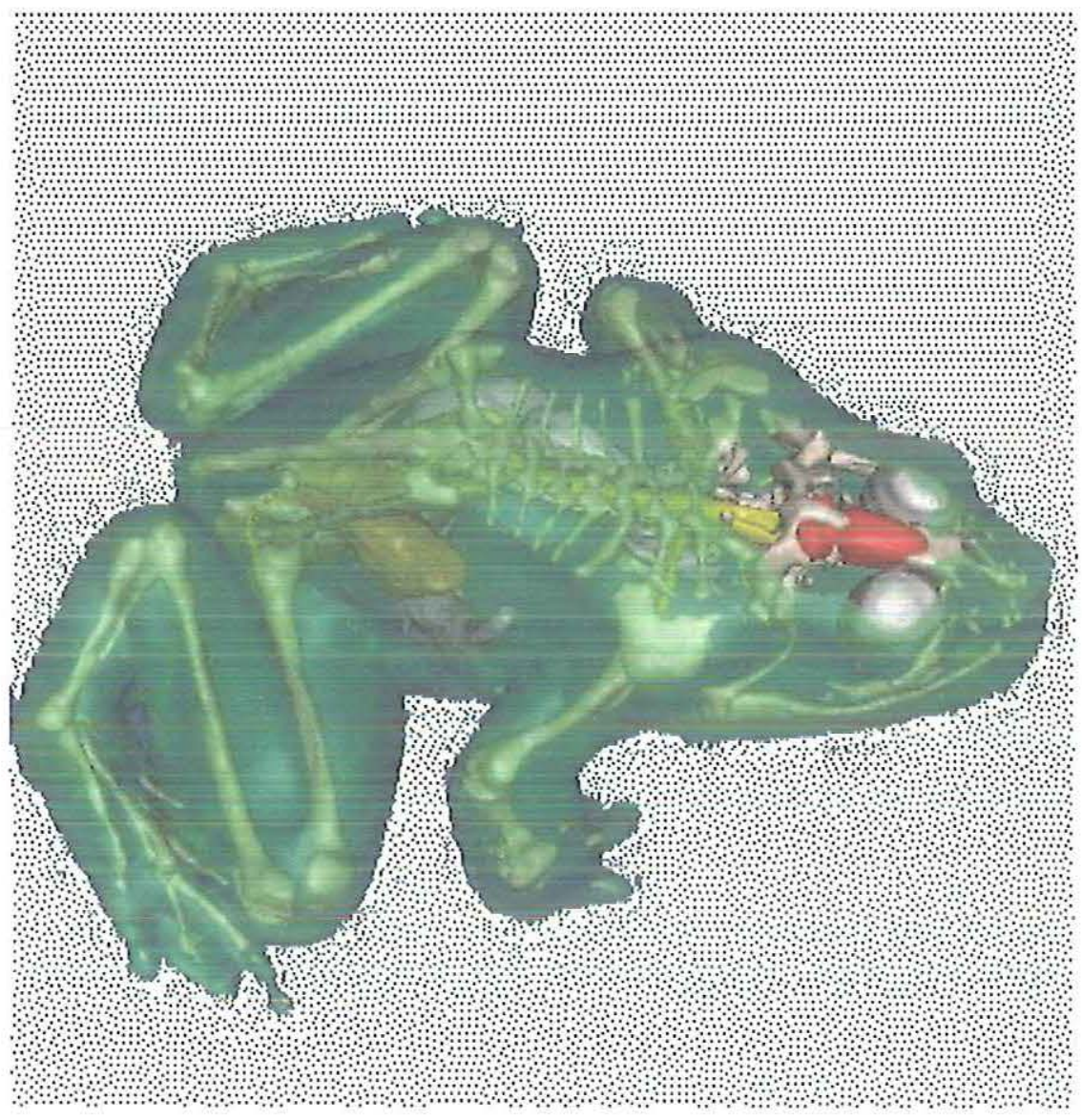

FIGURA 4.2. - The virtual creatures project - Stanford University 


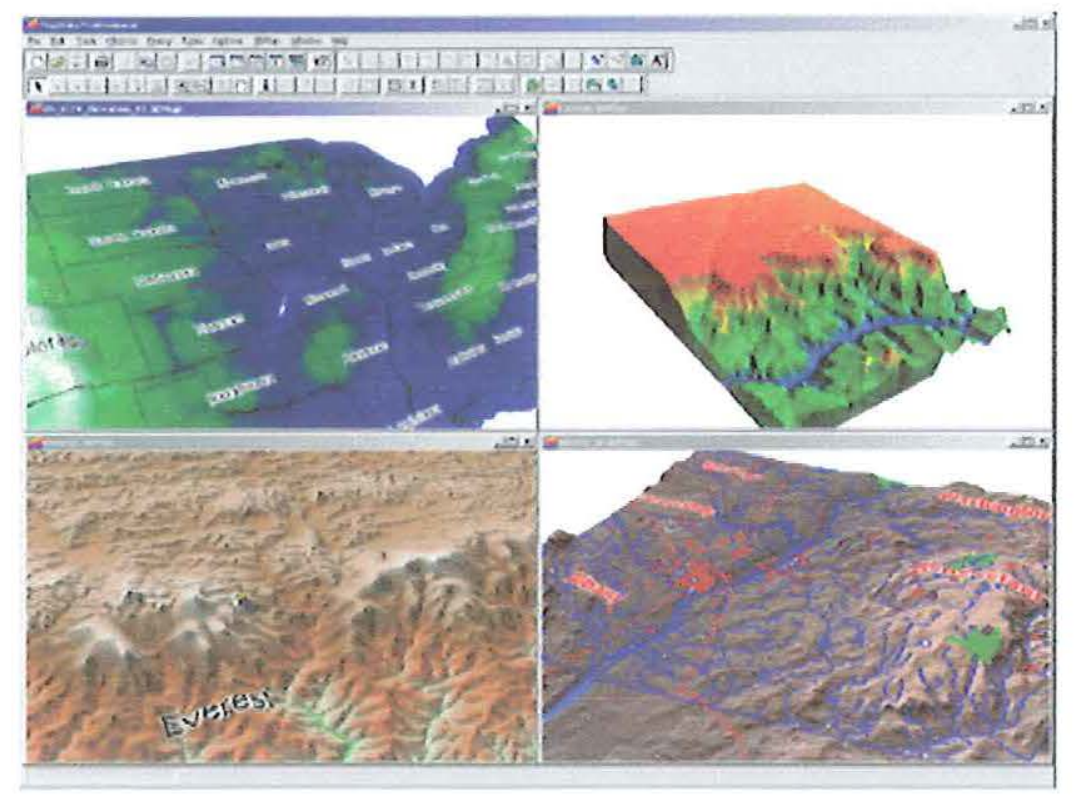

FIGURA 4.3.- MapInfo Corporation (NASDAQ: MAPS)

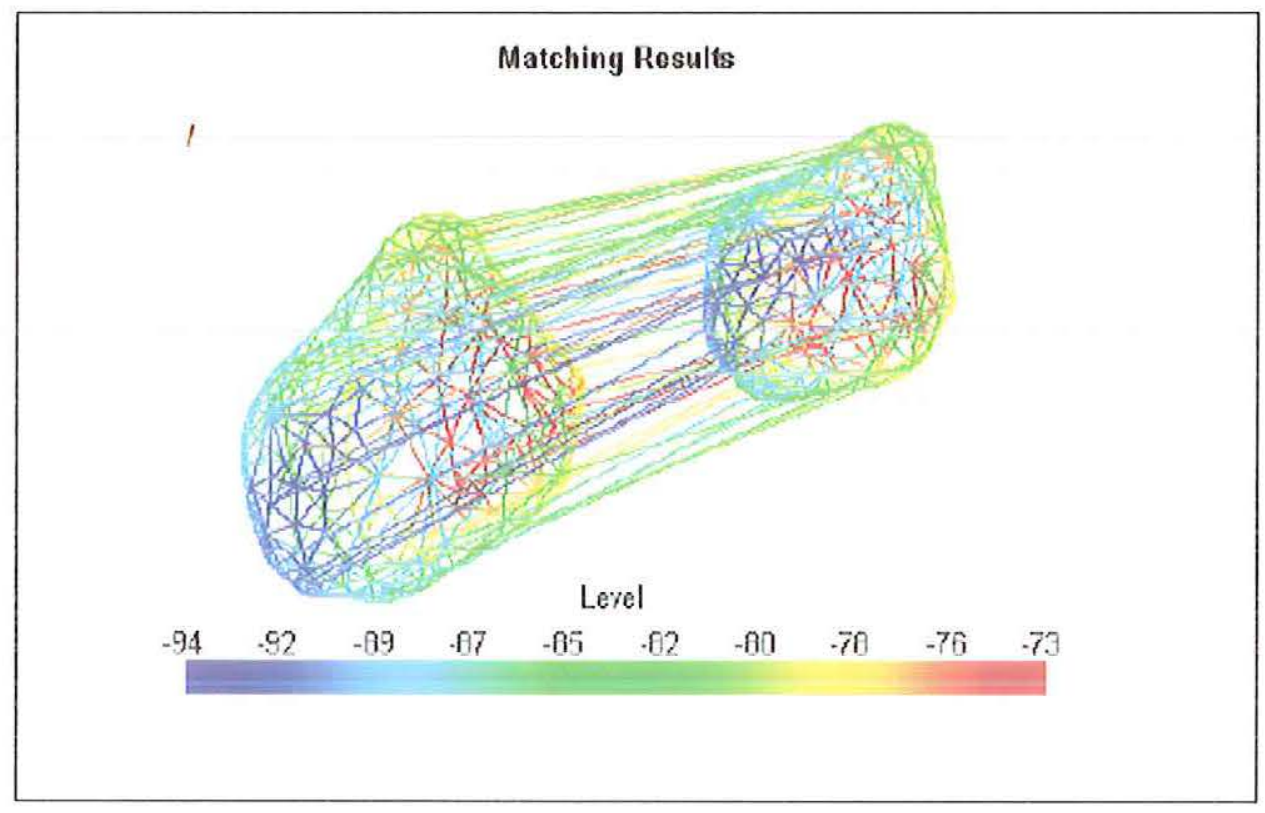

FIGURA 4.4.- Universidade do Porto - Portugal 
As figuras a seguir (Figuras 4.5, 4.6, 4.7 e 4.8), ilustram resultados de simulações realizadas no Laboratório de Aeronaves - EESC - USP visualizados com a ferramenta VTK utilizando programação em linguagem Tcl/Tk.

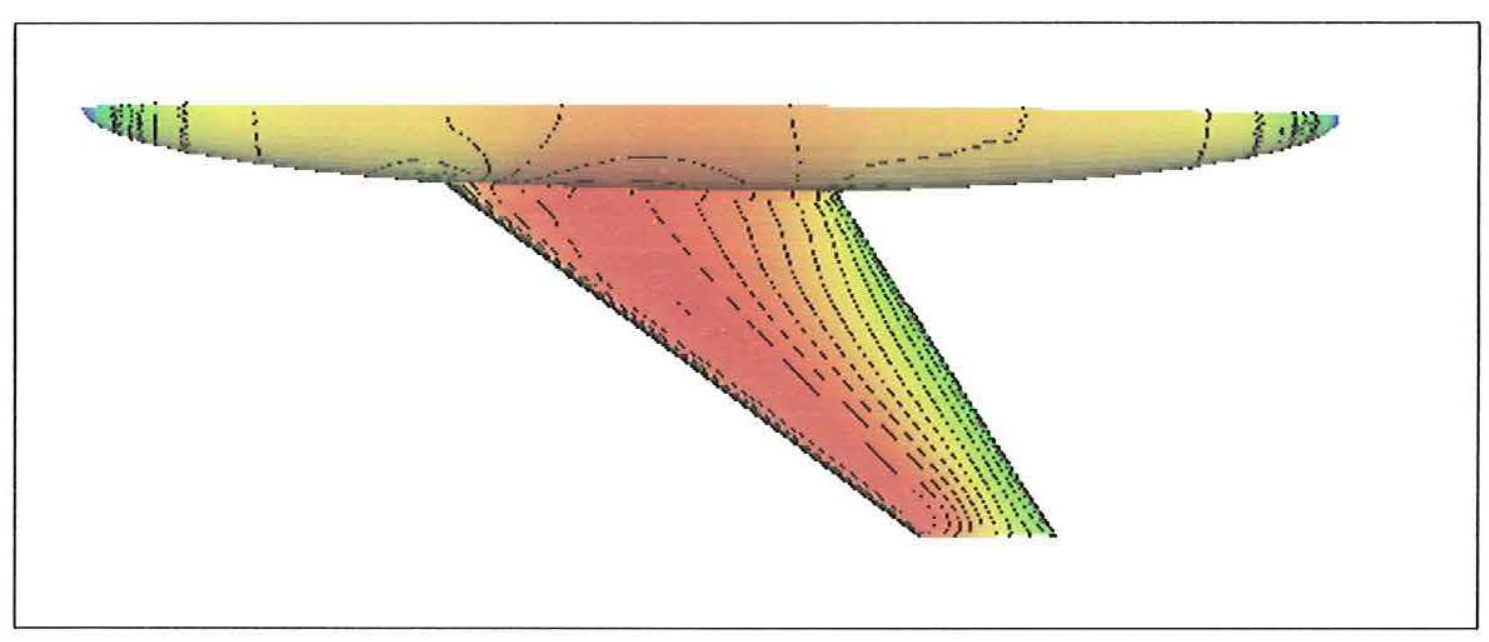

FIGURAS 4.5. - Exemplo asa/fuselagem.

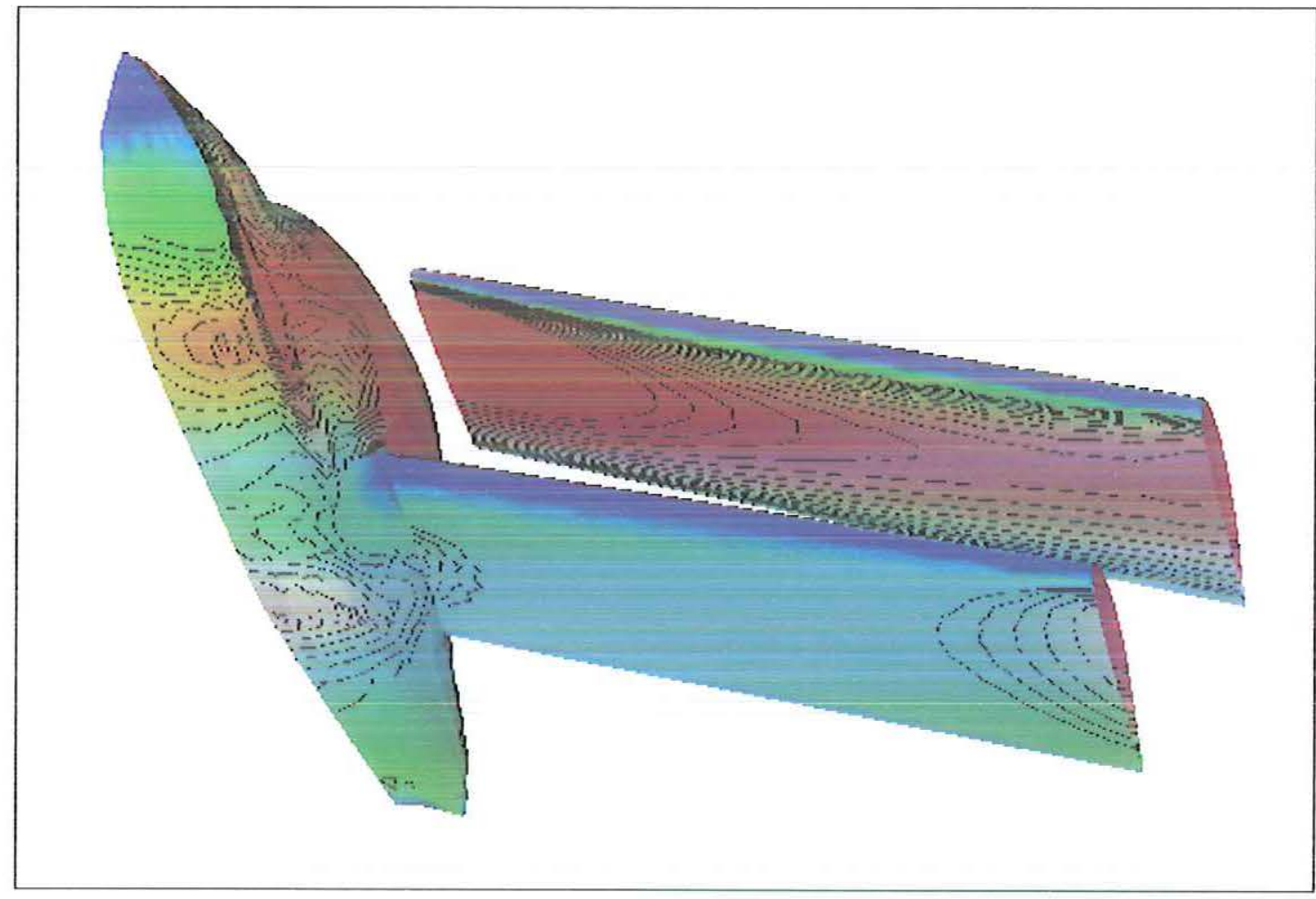

FIGURA 4.6. - Paturi. 


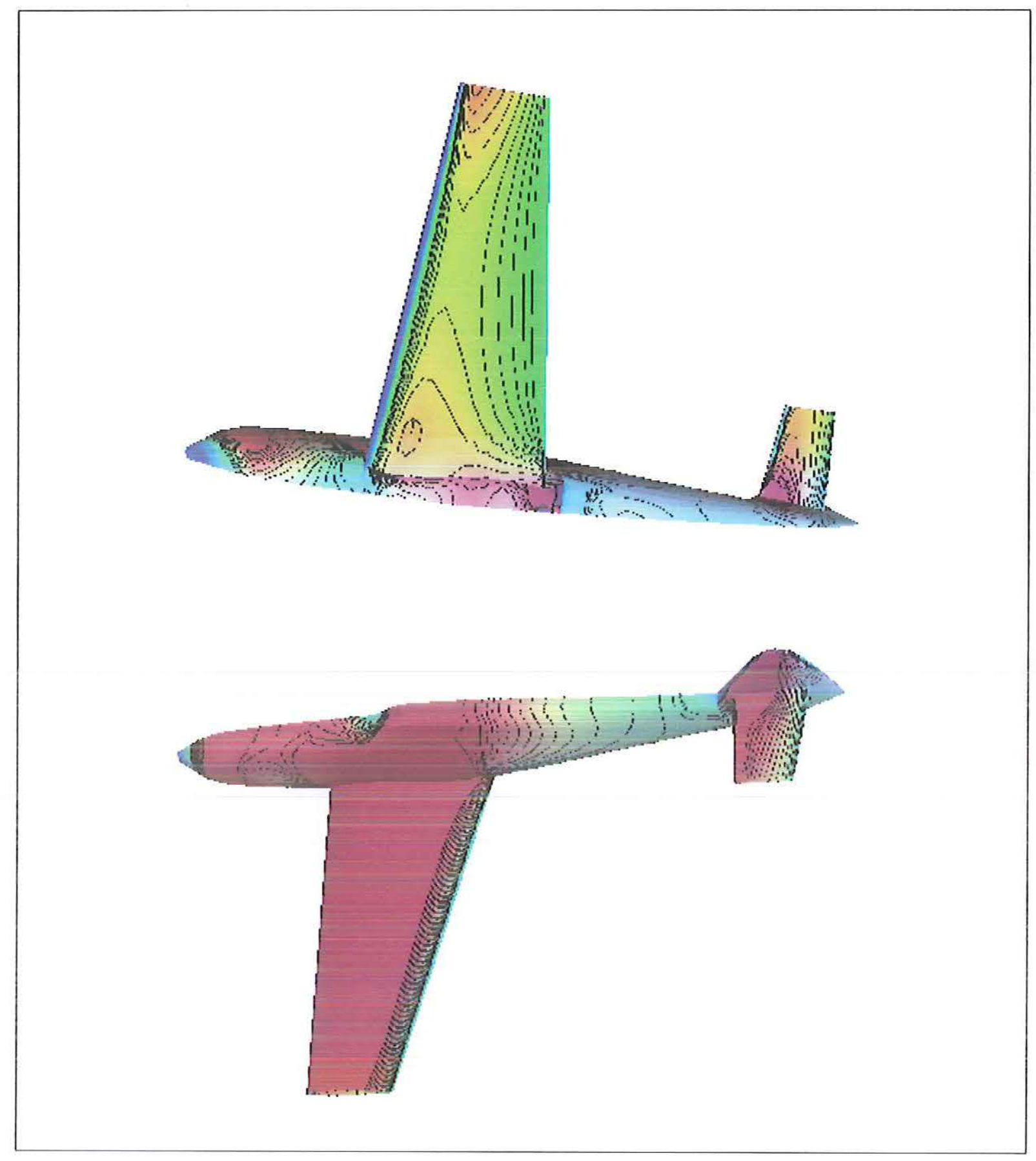

FIGURA 4.7. - Me109.

VISUALIZAÇÃO CIENTIFICA COMPUTACIONAL APLICADA A MODELOS AERODINÂMICOS SIMULADOS EM MÉTODO DOS PAINEIS. 


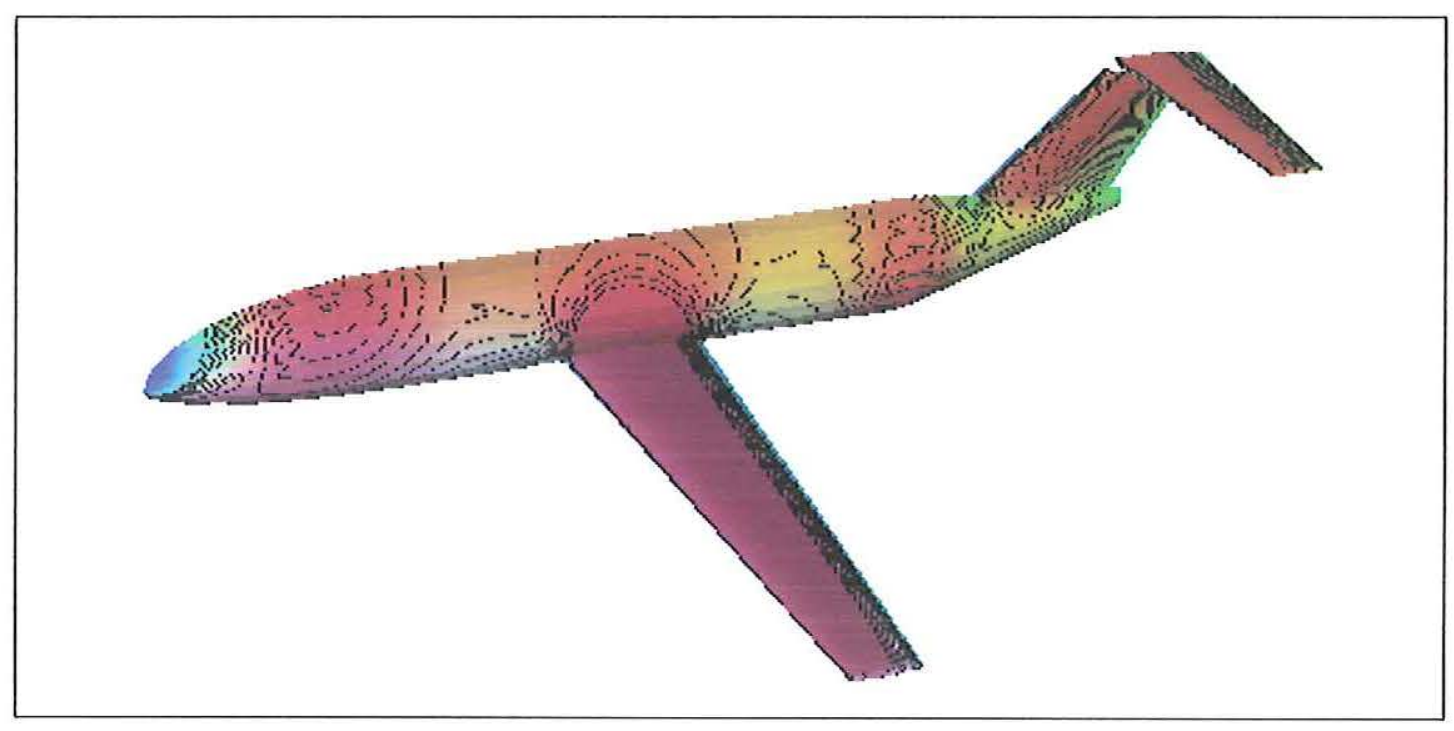

FIGURA 4.8. - Brasília. 


\section{Resultados}

O tipo de visualização que atende os principais requisitos para o caso de pequenos modelos aeronáuticos consiste em visualizar o campo escalar na superfície. Para o desenvolvimento desta visualização foram adotadas duas técnicas consagradas:

- $\quad$ Mapeamento por cor na superfície modelada por polígonos;

- Linhas de contorno de pressão constante na superfície modelada por polígonos.

As duas técnicas acima foram implementadas num script em $\mathrm{C}++$ para o VTK 3.1. A associação entre os objetos VTK empregados pode ser observada no pipeline apresentado na figura 5.1. Um objeto vtkPolyDataReader lê um arquivo texto ASCII em formato padrão VTK contendo o conjunto de dados com os pontos-amostra da superfície a ser visualizada, assim como a topologia da superfície poligonal que será formada entre estes pontos e o valor escalar associado a cada um. Em seguida, parâmetros são definidos para um filtro de linhas de contorno vtkContourFilter, que processa os escalares gerando os contornos para constantes pré-definidas. Os parâmetros são definidos para uma tabela de mapeamento de valores escalares para tons de cores, representada por um objeto vtkLookupTable. Finalmente, a superfície é renderizada com as cores atribuídas pela tabela e com as linhas de contorno geradas.

Além dos objetos descritos no pipeline podemos destacar o uso do objeto vtkScalarBarActor que desempenha o papel de legenda a partir da leitura dos dados contidos na tabela de cores. $\mathrm{O}$ uso do objeto facilita a compreensão da associação de cores ao valor numérico (valor de $\mathrm{CP}$ ) correspondente.

A gama de variação de cores no mapa apresentado foi estabelecida sobre o espectro, variando do azul para as pressões mais baixas ao vermelho para as pressões mais altas. 


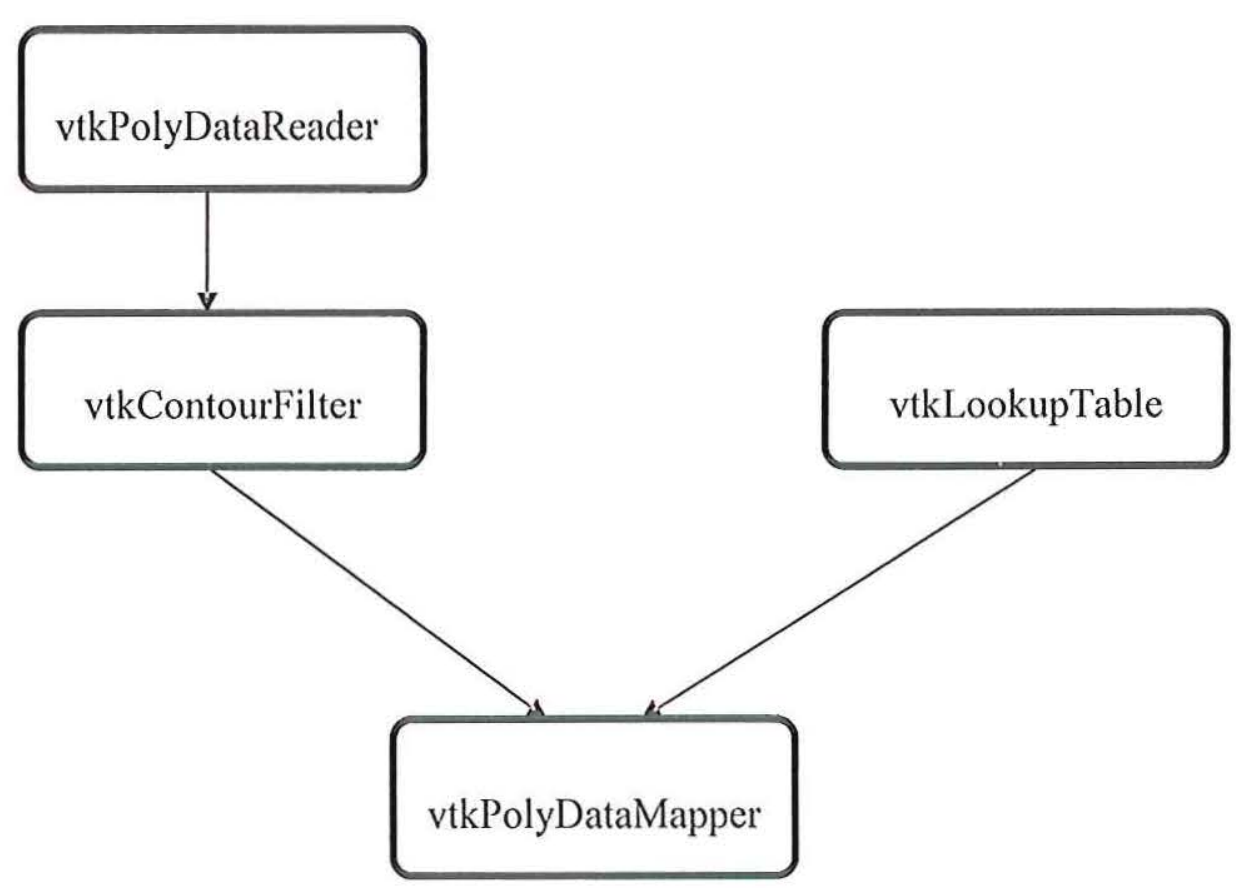

FIGURA 5.1. - Pipeline de Renderização.

O algoritmo descrito foi aplicado a dois modelos simulados em software de método dos painéis, descrito no Apêndice $\mathrm{A}$, o Panflo 2.0. O mesmo possui uma rotina de conversão que gera um arquivo de saída em formato VTK.

\subsection{Arapuca}

A aeronave Arapuca foi criada e construída pela equipe Aerodesign da EESC - USP para a competição SAE Brasil Aerodesing 2002, possuindo como principal característica alta sustentação a baixos números de Reynolds, com o intuito de carregar uma carga prevista cumprindo uma determinada missão estipulada pelas regras da competição.

O protótipo Arapuca tem asas dispostas em tandem sendo que a asa dianteira não possui diedro nem enflechamento, o perfil utilizado para esta foi o Selig 1223 e sua corda mede $220 \mathrm{~mm}$, enquanto que a asa traseira possui diedro e enflechamento positivos, o perfil é o Clark-y e sua corda mede $155 \mathrm{~mm}$. A asa traseira ainda possui winglets com superfícies de comando para o controle direcional e ailerons para o controle de rolagem. O controle de arfagem é feito pela asa dianteira e esta configuração exclui a necessidade de empenagem. Além disso, cabe colocar que as asas não 
possuem nenhuma torção e as seções dos aerofólios têm suas cordas enfileiradas sendo o valor de Alpha (ângulo de ataque) igual para ambos, ou seja, o ângulo das linhas de corda de ambos, referente à direção de vôo. Lembrando que o efeito de "downwash" da asa dianteira, ou seja, a tendência do escoamento saindo da asa possui um componente vertical descendente que faz com que a asa traseira de fato possua um ângulo de incidência menor, sendo que o ângulo de incidência é aquele entre a nova direção geral do escoamento e a linha de corda local da asa. Assim Alpha, o ângulo de ataque, possui um único valor. A aeronave descrita acima é mostrada num desenho esquemático na figura 5.2. a seguir.

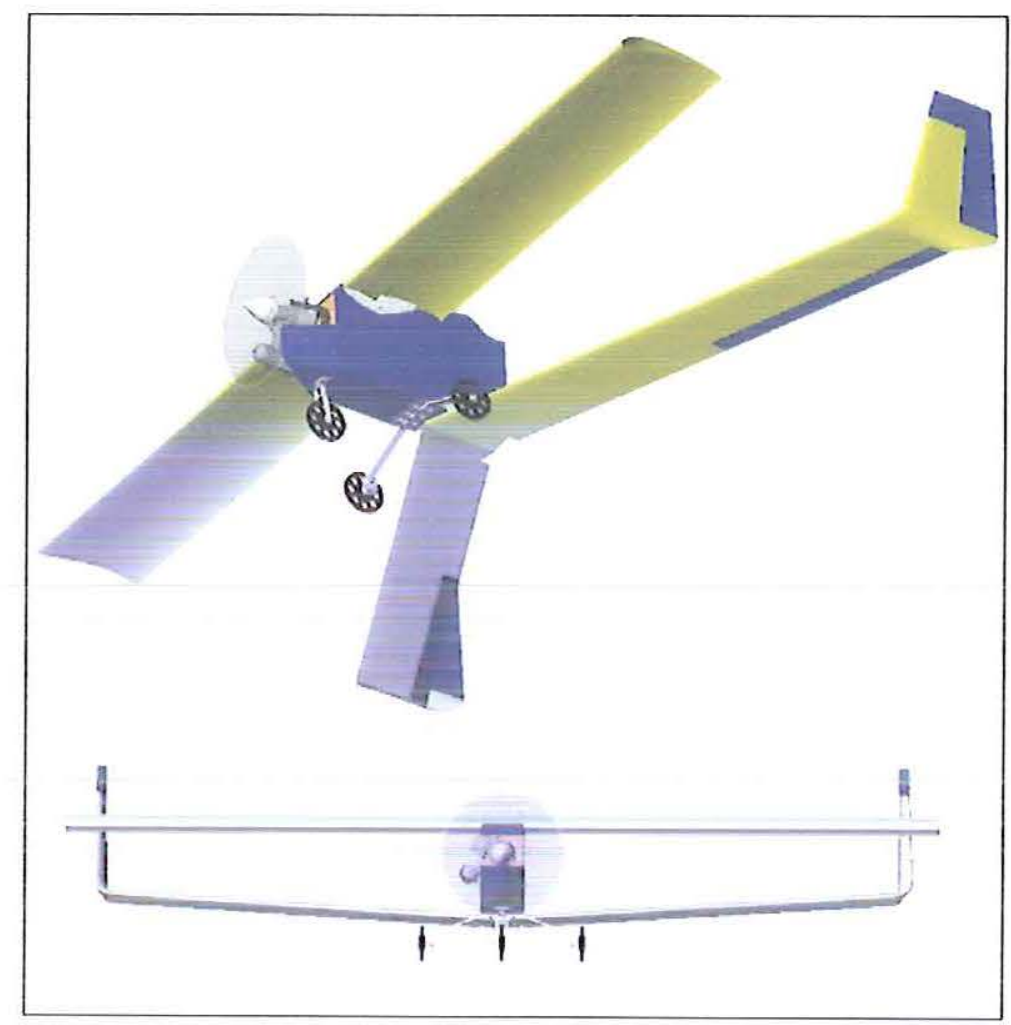

FIGURA 5.2. - Desenho Esquemático da Aeronave Arapuca.

As asas de um lado da aeronave foram simuladas a um Mach de 0.055 , o que equivale à velocidade média de vôo da aeronave, e variando Alpha em 0, 5, 10 e 15 graus. Em seguida submetidas à rotina de visualização, como apresentam as figuras 5.3, 5.4, 5.5 e 5.6 abaixo. As setas em vermelho ilustram a direção e o sentido do escoamento, de forma aproximada, apenas para deixar claro a posição das asas. 


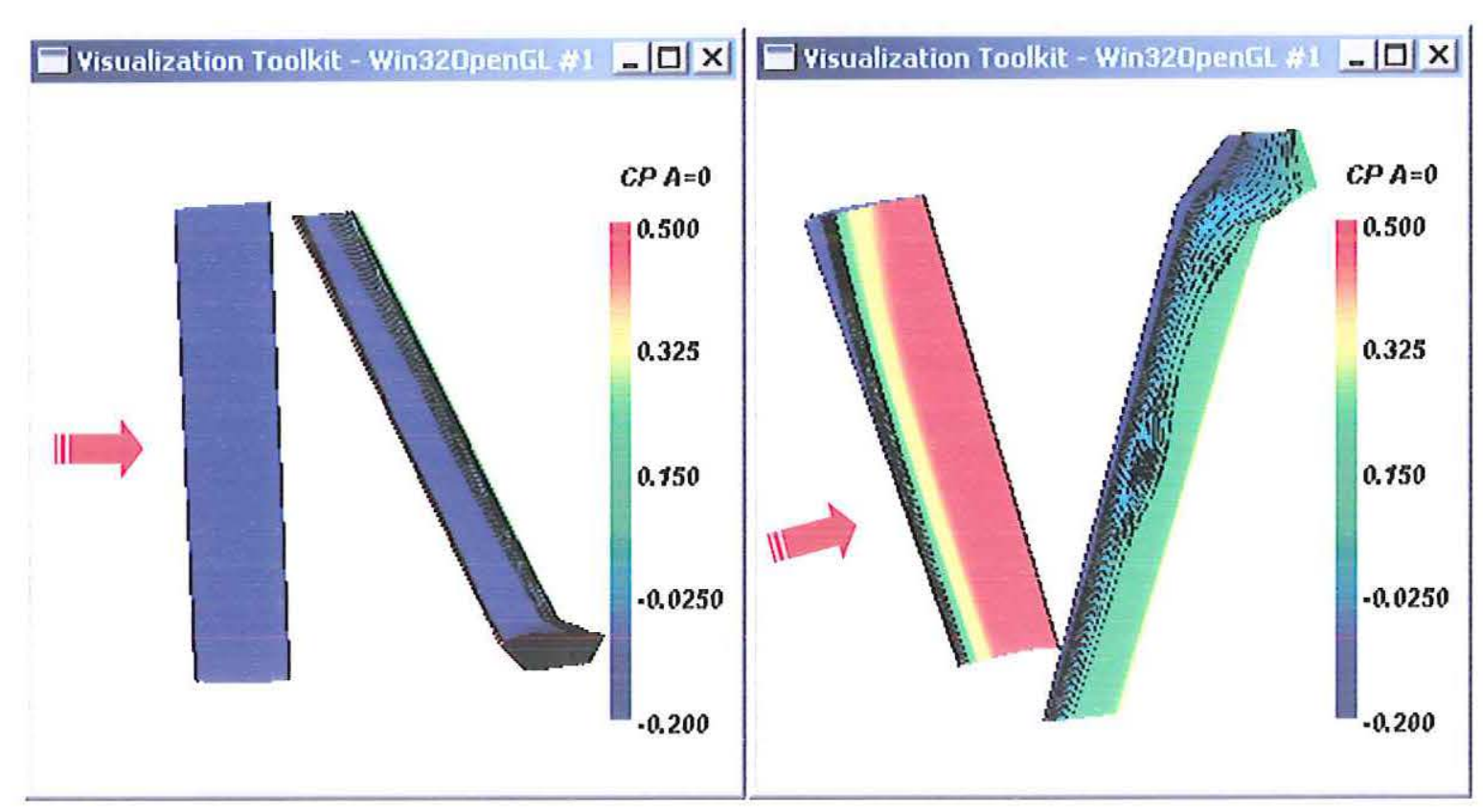

FIGURA 5.3. - Asas da Aeronave Arapuca com Alpha=0 (À esquerda extradorso e à direita intradorso).

As figuras geradas para o intradorso desta aeronave causam dificuldade de entendimento a primeira vista devido a sua posição. Para uma vista mais abrangente do modelo, as asa aparecem um pouco inclinadas dando a falsa impressão em relação às raízes, mas é apenas o efeito tridimensional.

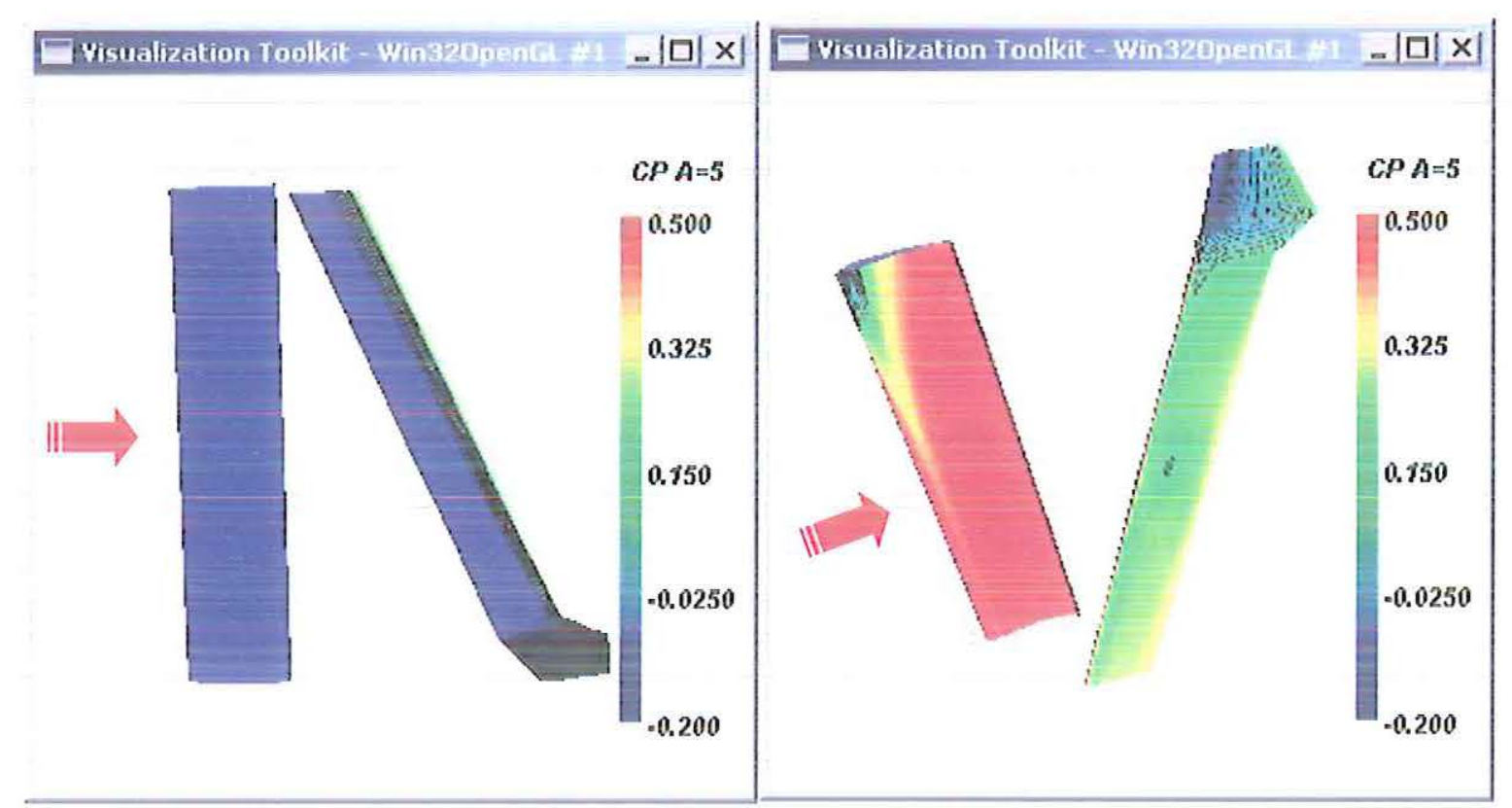

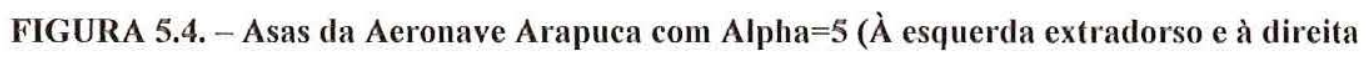
intradorso).

VISUALIZAÇÃO CIENTIFICA COMPUTACIONAL APLICADA A MODELOS AERODINÂMICOS SIMULADOS EM MÉTODO DOS PAINEIS. 


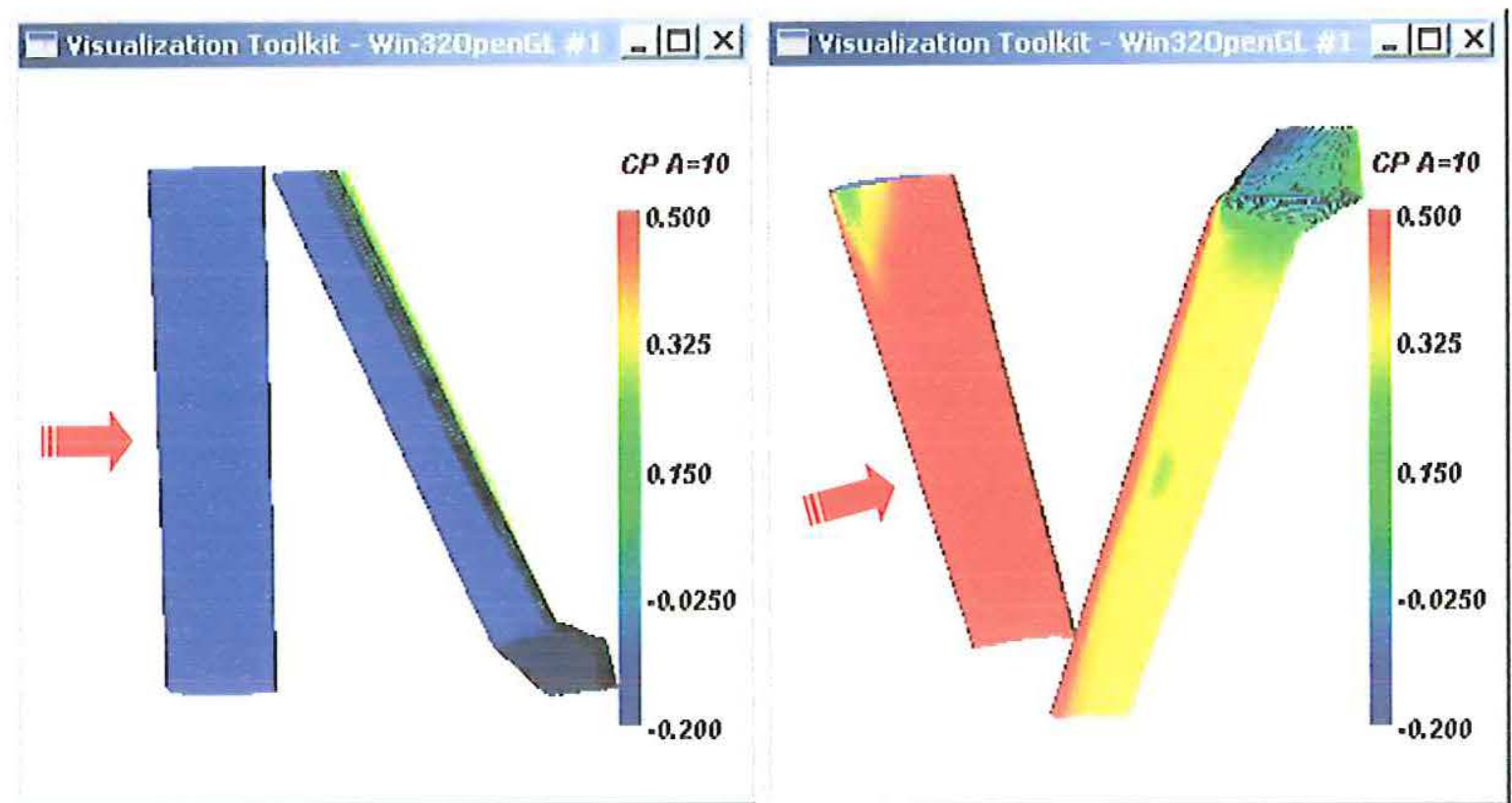

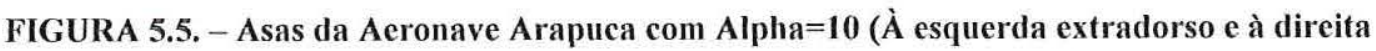
intradorso).

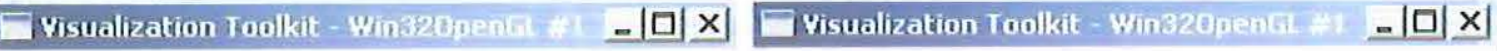

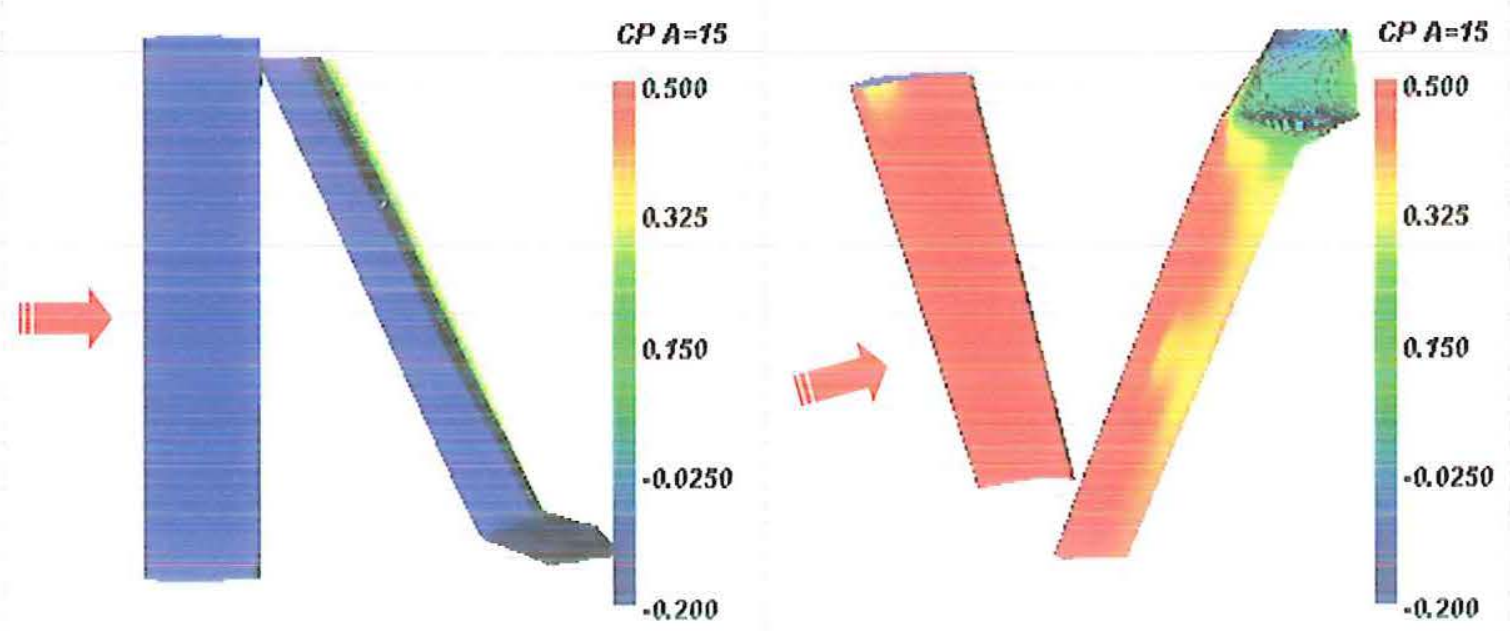

FIGURA 5.6. - Asas da Aeronave Arapuca com Alpha=15 (̇̀ esquerda extradorso e à direita intradorso).

VISUALIZAÇÃO CIENTIFICA COMPUTACIONAL APLICADA A MODELOS AERODINÂMICOS SIMULADOS EM MÉTODO DOS PAINEIS. 


\subsection{Seneca.}

O segundo modelo a ser apresentado é baseado em um meio-modelo de túnel de vento devivado do Piper/Embraer Seneca III como ilustra a figura 5.7. Foi simulada apenas a asa, sem a nacelle e o aumento de corda da fuselagem (ou raiz), que aparecem na figura 5.7, com a configuração do aerofólio NACA $652-215$ original. As condições de simulação numérica e de visualização são as mesmas do modelo anterior com excȩ̧ão do numero de Mach que foi de 0.034 que equivale às condições de vôo para este modelo no túnel de vento.

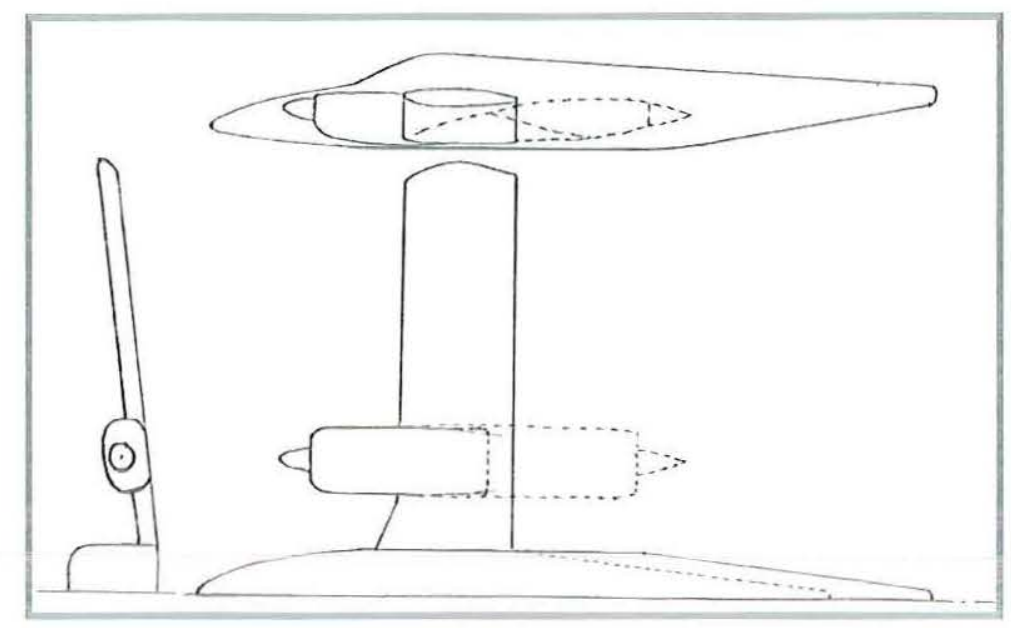

FIGURA 5.7. - Desenho Esquemático do meio-modelo Seneca.

Para cada ângulo simulado apresenta-se uma figura com vista do bordo de ataque e uma figura apresentando as duas faces (o intradorso e o extradorso) da asa. Por este exemplo ter uma visualização conhecida e trivial fica evidente a validade da simulação e visualização computacional.

Para as figuras $5.8,5.9,5.10$ e 5.11 , deve-se observar também o aspecto tridimensional de acordo com a posição escolhida para a melhor vista do bordo de ataque. Na Primeira figura de extradorso e nas demais de intradorso. Isto feito para observar um conhecido fenômeno da variação da localização do ponto de estagnação em relação à variação do ângulo de ataque. 
DYisualization Toolkit - Win329penal $=|\square| x \mid$

Raiz $C P A=0$

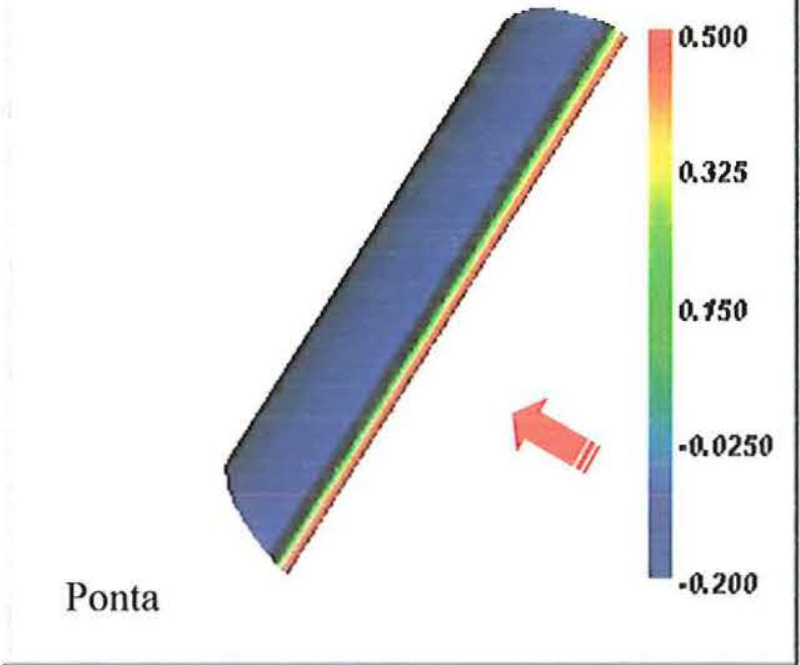

FIGURA 5.8. - Asa do modelo com Alpha=0 (Vista do bordo de ataque).

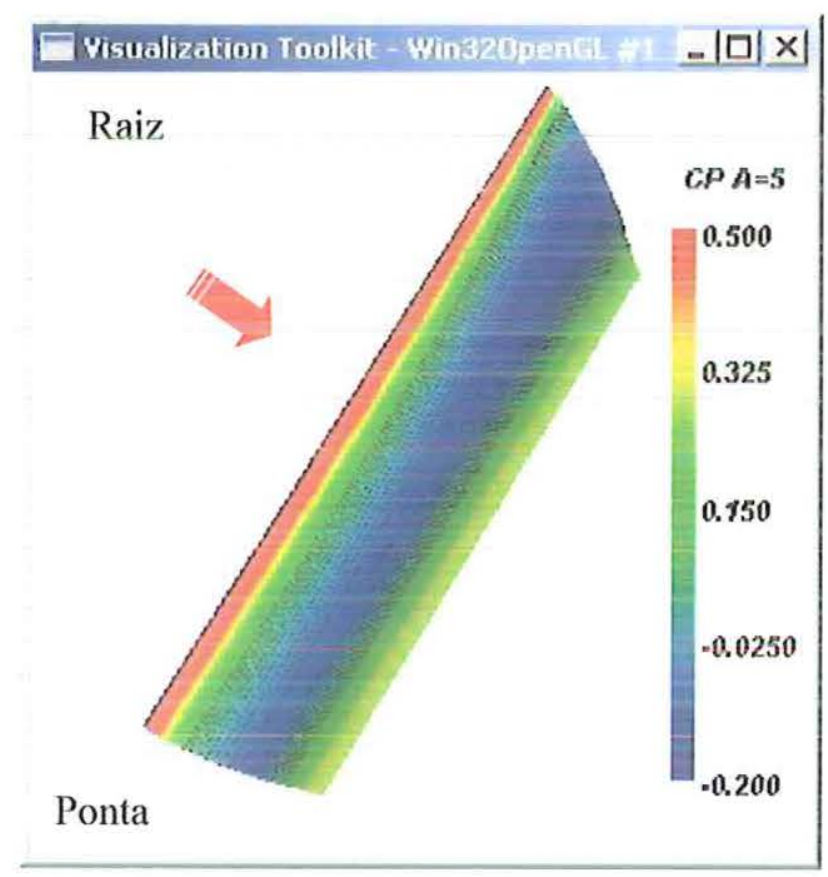

FIGURA 5.9. - Asa do modelo com Alpha $=5$ (Vista do bordo de ataque). 


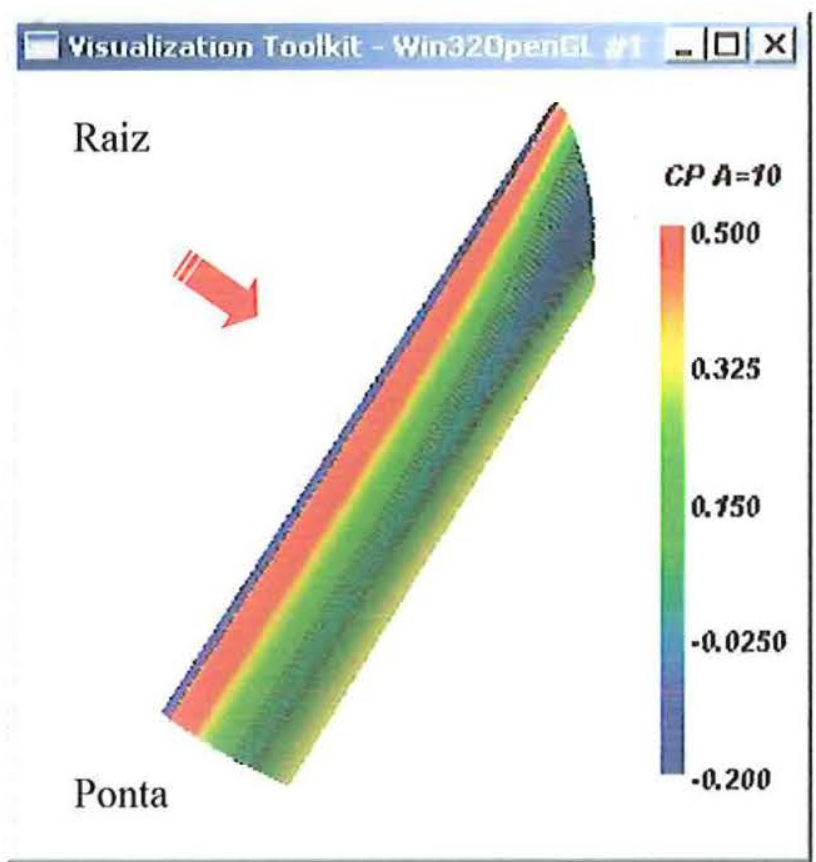

FIGURA 5.10. - Asa do modelo com Alpha=10 (Vista do bordo de ataque).

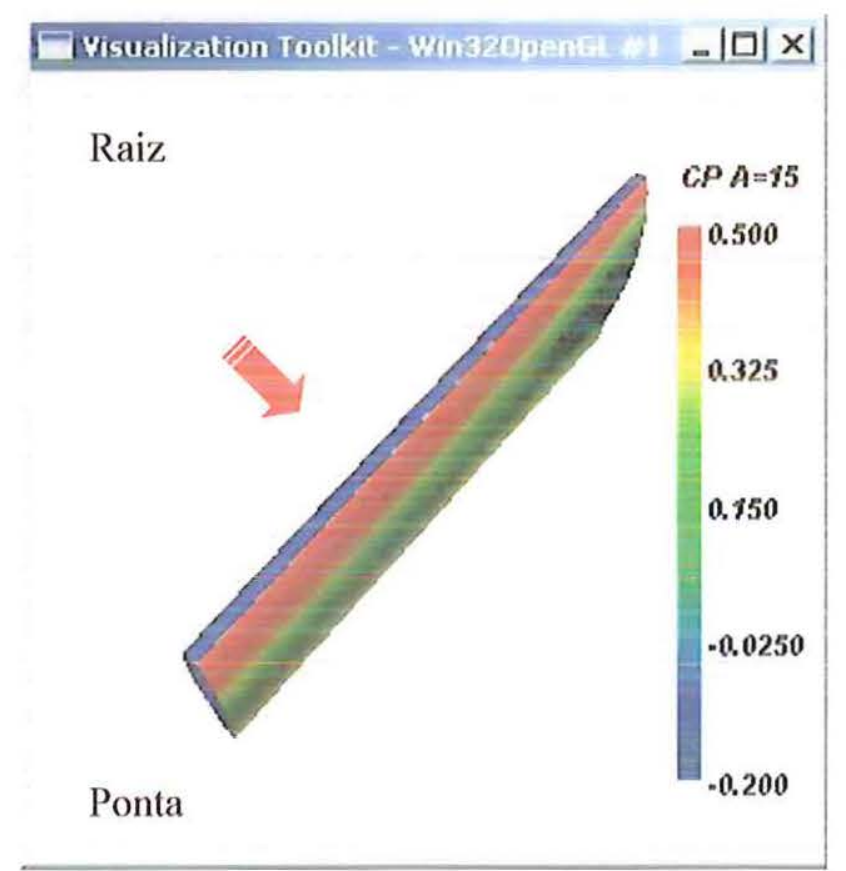

FIGURA 5.11. - Asa do modelo com Alpha=15 (Vista do bordo de ataque). 


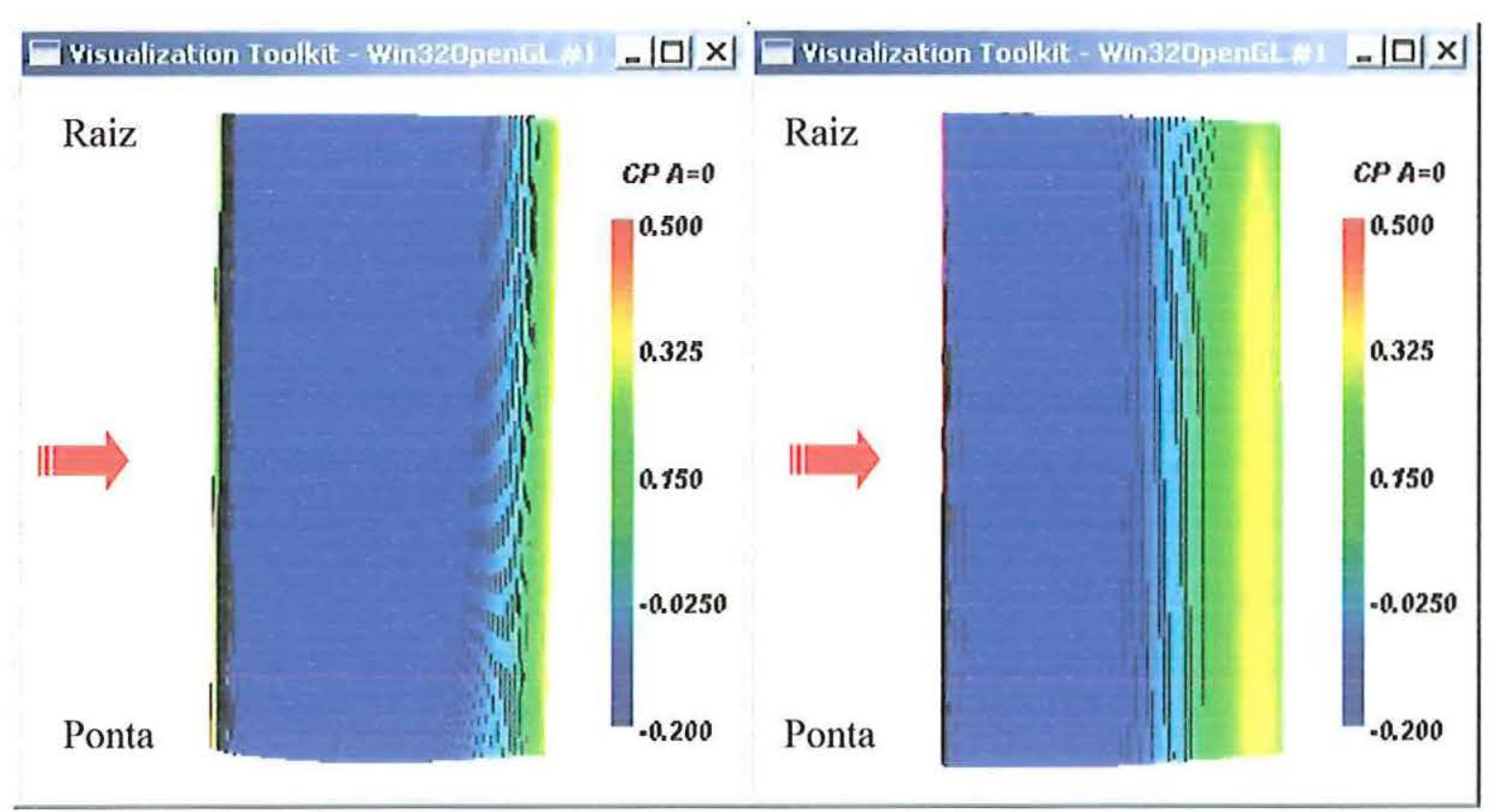

FIGURA 5.12. - Asa do modelo com Alpha=0 (À esquerda extradorso e à direita intradorso).

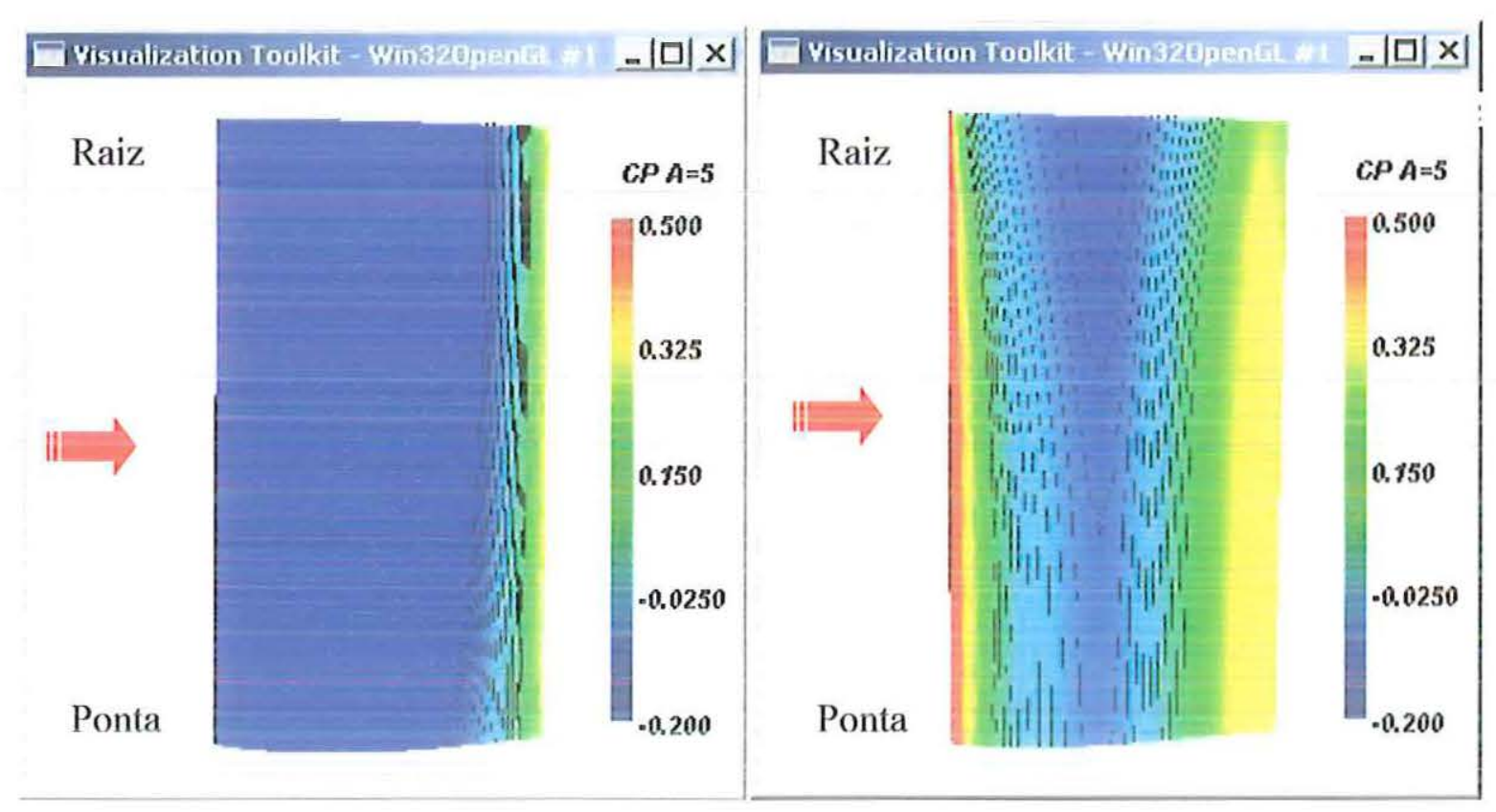

FIGURA 5.13. - Asa do modelo com Alpha=5 (À esquerda extradorso e à direita intradorso). 


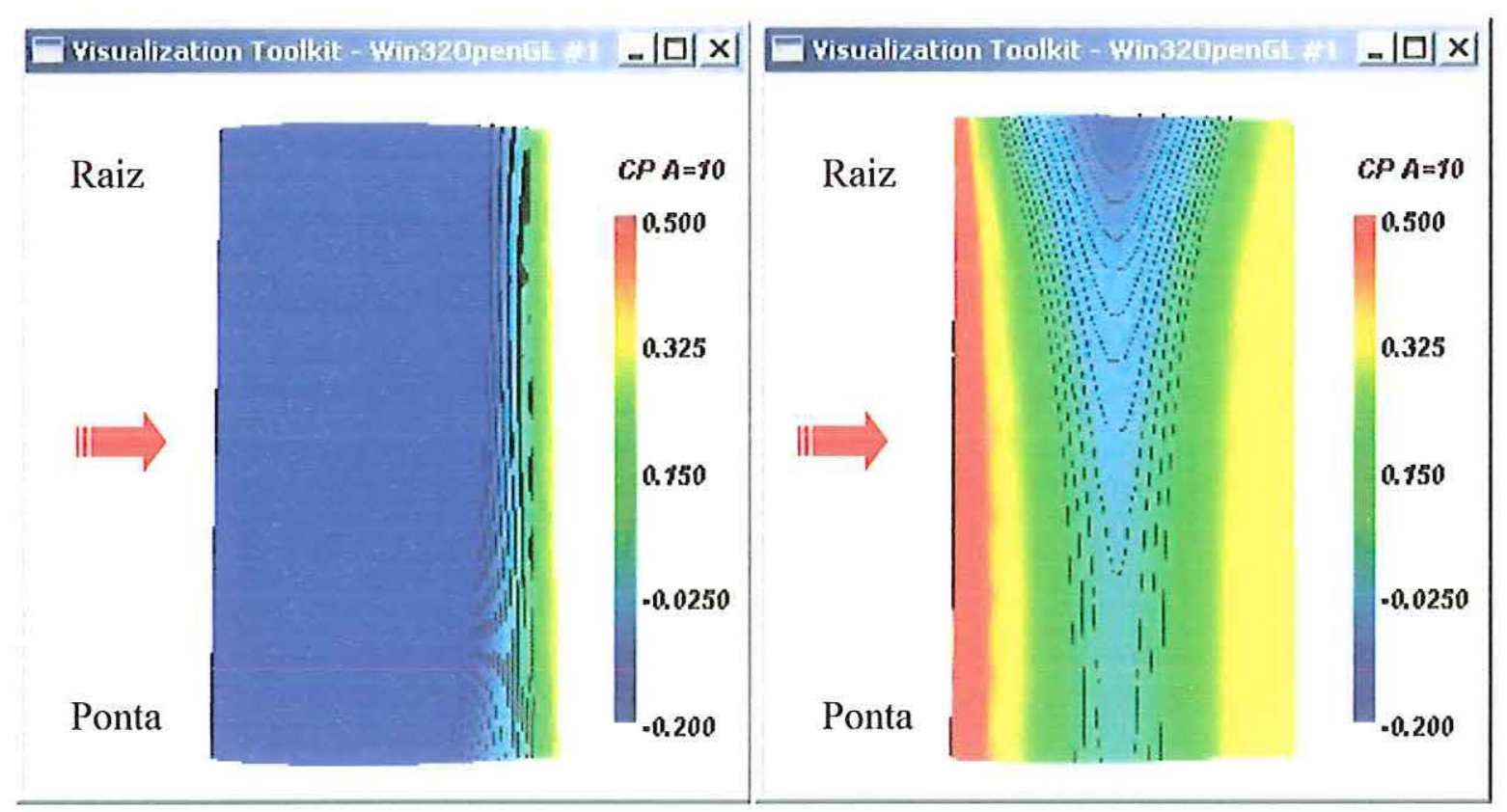

FIGURA 5.14. - Asa do modelo com Alpha=10 (À esquerda extradorso e à direita intradorso).

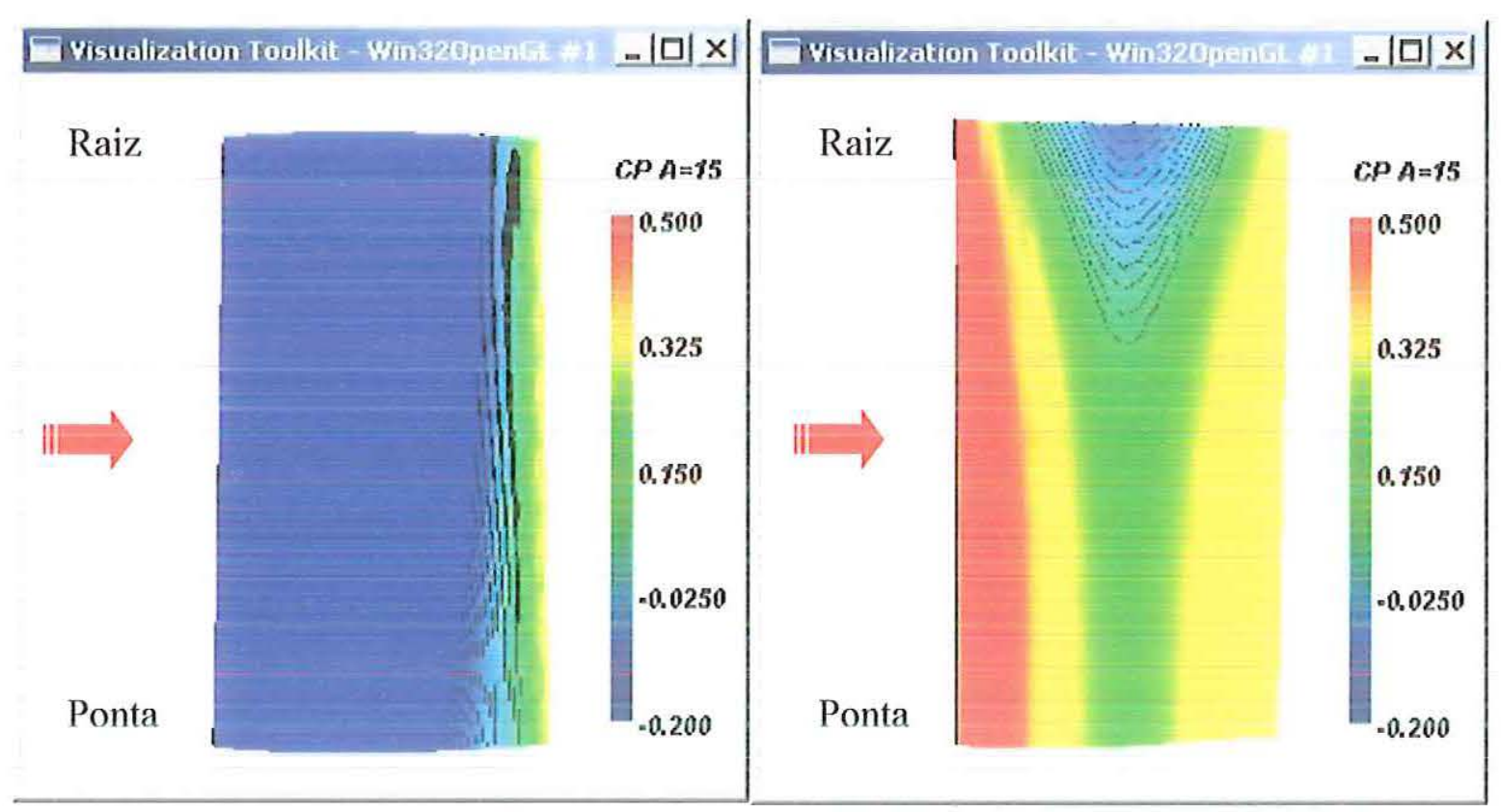

FIGURA 5.15. - Asa do modelo com Alpha=15 (À esquerda extradorso e à direita intradorso). 


\subsection{Análise dos Resultados}

As rotinas de visualização podem ser incrementadas, com um refinamento na tabela de cores, para uma melhor observação dos resultados do extradorso compreendidos na cor azul. Estes dados possuem uma variação um pouco mais minuciosa que não pode ser vista no modelo atual.

As Figuras 5.8, 5.9, 5.10 e 5.11, como descrito na seção anterior, foram geradas para uma melhor análise da variação do ponto de estagnação, para qualquer seção da asa ao longo da envergadura. Este fenômeno pode ser observado no limite entre o vermelho e o azul, localizados no bordo de ataque e se deslocando para o intradorso da asa à medida que seu ângulo de ataque aumenta.

As demais figuras ilustram os efeitos do escoamento na superfície das asas. Mais especificamente o $\mathrm{Cp}$ (coeficiente de pressão) sendo um valor adimensional, equivalente ou proporcional aos valores de pressão estática.

Deve-se lembrar que a simulação em questão foi realizada em método dos painéis, um método potencial, ou seja, livre de efeitos viscosos. Isto ocasiona perda de eficiência do método para altos ângulos de ataque uma vez que nestas condições existem efeitos viscosos iminentes.

Entretanto, os resultados são bastante úteis, em sua maioria, na identificação e análise de fenômenos e efeitos aerodinâmicos já citados, principalmente no intradorso onde a distribuição de cores é mais favorável à observação até mesmo dos efeitos que a fuselagem provoca no escoamento sobre a superfície da asa. 


\section{Conclusões}

Neste foram apresentadas visualizações para modelos aerodinâmicos para fins de observação e comparação com dados experimentais. Acredita-se que a realização deste trabalho cumpriu os principais objetivos dentro do escopo adequado a um trabalho de mestrado.

Os dois principais assuntos pesquisados para a execução deste trabalho foram, Método dos Painéis que é um assunto de grande extensão refletindo assim sua grande importância e sua utilização ao longo das ultimas três décadas, e visualização que, apesar de ser um assunto novo está sendo amplamente estudado e utilizado nas mais diversas áreas.

O Método dos Painéis, apesar de suas limitações contribuiu para as simulações numéricas as quais este trabalho utilizou-se através do software já citado, sem o qual este trabalho não poderia ter o mesmo intuito de ser uma ferramenta completa para o Laboratório.

Quanto ao que diz respeito às rotinas de visualização, conforme pesquisado e estudado em disciplina, ainda há muito para ser feito, tanto em relação a potencia das ferramentas utilizadas quanto às necessidades de visualização que podem surgir. Muitos dos trabalhos vistos são de foro especifico, ou seja, cada visualização tem atendido às necessidades de uma área e desta forma procurou-se fazer, atendendo as necessidades especificas de visualização de corpos imersos em fluxo livre. Como já dito, há muito ainda a ser feito inclusive uma interface mais amigável com os possíveis usuários, desde a simulação até a visualização. Enquanto isso não pode ser feito houve a preocupação de prestar uma ajuda àqueles que queiram utilizar o processo completo, colocando no apêndice B deste trabalho uma espécie de manual que contém as principais informações de como preparar os arquivos, de como simular e de como visualizar usando $\mathrm{C}++$.

Contudo o presente trabalho dá inicio a uma gama de pesquisas em Simulação Numérica de baixo custo, possibilitando a visualização de dados e desvendando fenômenos antes difíceis de serem vistos em antigas Visualizações de Túnel de Vento. Além do beneficio de ser uma ferramenta potente e de baixo custo computacional, ainda existe o beneficio de usar uma biblioteca open-source o que o torna uma ferramenta extremamente barata em relação aos demais softwares de mesmo objetivo. 
As simulações numéricas e dados experimentais do laboratório estarão dando um grande passo para o avanço de interpretação e análise de dados com um produto da própria Universidade. Além do acesso aos códigos fontes e o aprendizado que isso representa é possível se ter certeza de como foi feito e assim, para que tipo de aplicações usar. 


\section{Referências Bibliográficas.}

AL-KHALIL, K. M.; KEITH JR, T. G.; WITT, K. J. (1997) - "Icing Calculations on a Typical Commercial Jet Engine Inlet Nacelle", Journal of Aircraft, v. 34, n.1, jan-feb, pp. 87-93

ALMOSNINO, D.; ROM, J. (1983) - "Calculation of Symmetric Vortex Separation Affecting Subsonic Bodies at High Incidence", AIAA Journal, v. 21, n. 3.

BRODLIE, K.W.; CARPENTER, L. A.; EARNSHAW, R. A.; GALLOP, J. R.; HUBBOLD, R. J.; MUNFORD, A. M.; OSLAND, C. D.; QUARENDON, P. (Editors) (1992) - Science Visualization: Techniques and Applications, Ed. Springer Verlag.

BRYSON, S.; LEVIT, C. (1992) - "The Virtual Wind Tunnel", IEEE Computer Graphics and Applications, v. 26, n. 04, pp. 25-34.

CHEN, L. T.; YU, K. C.; DANG, T. Q. (1990) - "Transonic Computational Method for an Aftmounted Nacelle/Pylon with Power Effect", Journal of Aircraft, v. 27, n. 10, pp. 878-885.

COLTURATO, D. B.; OLIVEIRA, M. C. F. (2001) - "Ambiente Interativo para Visualização de Dados de Neurônios", Dissertação de mestrado do ICMC - Instituto de Ciências Matemáticas e Computação - USP - São Carlos 
DELMAECELLE, T.; HESSELINK, L. (Editor: Gallagher, R. S.) (1995) - “ A Unified Framework for Flow Visualization", Computer Visualization: Graphics techniques for Scientific and Engineering Analysis, CRC Press, Cap 5, pp. 129-170.

ELVINS, T. T. (1992) - “A Survey of Algorithms for Volume Visualization”, Computer Graphics, v. 26, n. 3 , ago.

GALLAGHER, R. S. - (1995) "Computer Visualization - Graphics Techniques for Scientific and Engineering Analysis ", Ed. CRC Press Inc.

GERSHON, N. - (1994) "From Perception to Visualization", in Rosemblum, L. et al. (eds.) Scientific Visualization, Advances and Challenges, Academic Press.

HELMAN, J.L.; HESSELINK, L. (1991) - "Visualizing Vector Field Topology in Fluid Flows", IEEE Computer Graphics and Applications, vol. 11, n. 3, pp. 36-46.

HESS, J. L. (1990) - "Linear Potential Schemes. In: Henne, P. A., ed. Applied Computational Aerodynamics. Washington, American Institute of Aeronautics and Astronautics Inc. Cap.2, pp. 2137. (Progress in Astronautics and Aeronautics).

KRAUS, W. (1978) - "Panel Methods in Aerodynamics." In: WIRZ, H. J., ed. Numerical methods in fluid dynamics. Cap.1, pp.237-297. New York, McGraw Hill.

KATZ, J.; PLOTKIN, A. (1991) - "Low Speed Aerodynamics: From Wing Theory to Panel Methods". New York, McGraw Hill.

LAMARRE, F.; PARASCHIVOIU, I. (1992) - "Efficient Panel Method for Vortex Sheet Roll-up", Journal of Aircraft, v.29, n. 1, jan-feb. 
LEONG, S. H. (1990) - "A Panel Method Computation for Oscillating Aerofoil in Compressible Flow", International Journal for Numerical Methods in Engineering, v. 29, pp. 559-578.

LETCHER JR, J. S. (1989) - "Convergence of Lift and Drag Predictions by a Morino Panel Method (VSAERO)", AIAA Journal , v. 27, n.8, pp.1019-1020.

LIU, D. D.; JAMES, D. K.; CHEN, P. C.; POTOTZKY, A. S. (1991) - "Further Studies of Harmonic Gradient Method for Supersonic Aeroelastic Applications", Journal of Aircraft, v. 28, n.9, sep.

MCCORMICK, B. H.; DE FANTI, T. A.; BROWN, M. D. (1987) - "visualization in Scientific Computing: A Synopsis", IEEE CG\&A, vol 7, n 4, pp. 61-70.

MARUYAMA, Y.; AKISHITA, S.; NAKAMURA, A. (1988) - "New Panel Method for Supersonic Flows about Arbitrary Configurations", Journal of Aircraft, v. 25, n. 3, mar.

MARTINS, A. L. (1993) - "Otimização computacional de superfícies aerodinâmicas com um método de malha de vórtices." Relatório (Estagio EMBRAER). Laboratório de Aeronaves, Escola de Engenharia de São Carlos, Universidade de São Paulo.

MARTINS, A. L. (1997) - "Estudo de Revisão, Implementação e Aplicação de Método de Painéis em Aerodinâmica.", 200P Dissertação (Mestrado) - Escola de Engenharia de São Carlos, Universidade de São Paulo.

MARTINS, A. L.; OLIVEIRA, M. C. F.; MINGHIM, R. (1997) - "Visualização Cientifica em Mecânica dos Fluídos", Notas do ICMC - Instituto de Ciências Matemáticas e Computação n.34 São Carlos, Universidade de São Paulo. 
NONATO, L. G.; MINGHIM, R.; OLIVEIRA, M. C. F.; TACARES, G. (2001) - "A Novel Approach for Delaunay 3D Reconstruction with a Comparative Analysis in the Light of Applications", Computer Graphics Forum, v.20, n.2, pp. 161-174.

SCHROEDER, W. J.; AVILA, L. S.; HOFFMAN, W. (2000) - "Visualizing with VTK: A Tutorial", IEEE Computer Graphics and Applications, sep-out.

SCHROEDER, W.; MARTIN, K.; LORENSEN, B. (1998) - "The Visualization Toolkit - an object-oriented approach to 3D graphics", Prentice Hall.

SMITH, S.C.; KROO, I. M. (1993) - "Computational of Introduced Drag for Elliptical and Crescent-shaped Wings." Journal of Aircraft, v.30, n.4, pp. 446-452, Jul-Ago.

SRIVASTAVA, A.; MOOK, D. T. (1994) - "Redundancy in the Discrete-vortex Method for Closed Bodies", Journal of Aircraft, v. 31, n. 6 ..

SUIKAT, R.; FAROKHI, S. (1988) - "Method of Optimize Nacelle Shape in a Supersonic Cruise Aircraft", Journal of Aircraft, v. 25, n.8, pp. 717-723.

TAVARES, J. M. R. S.; BARBOSA, J.; PADILHA, A. J. - (2002) "Apresentação de um Banco de Desenvolvimento e Ensaio para Objetos Deformáveis ", Revista Eletrônica de Sistemas de Informação, v.01, n.01, nov. http://www.presidentekennedy.br/resi

YOO, S.; STRASH, D. J. (1990) - "Zonal Approach to V/Stol Aerodynamics", Journal of Aircraft, v. 27, n. 10 , pp. $866-872$.

WATT, A.; WATT, M. (1992) - Advanced Animation and Rendering Techniques: Theory and Practice, Addison-Wesley. 


\section{O MÉtodo de IMPLEMENTAÇÃO DO PANFLO2.0. APÊNDICE $\mathbf{A}$}




\section{O método de implementação do PanFlo2.0.}

A filosofia de implementação do PanFlo2.0 apresentada pelo autor (MARTINS, 1997) foi a de que o método resultante fosse o mais genérico possível, ou seja, que não fosse voltado para nenhuma aplicação específica dentro do contexto da aerodinâmica.

Assim o método deveria ser o mais simples possível, sem o encargo de ambas as etapas de pré e pós-processamento necessários a um certo tipo de aplicação. Então, por exemplo, o algoritmo principal deveria receber como entrada a geometria dos painéis da configuração a ser analisada, e não as coordenadas do aerofólio de uma asa para a geração da geometria correspondente. Assim sendo, quaisquer informações pertinentes a uma aplicação especifica deveriam ser pré-processadas num programa de interface especialmente projetado para aquela aplicação.

De maneira semelhante, a saída de dados deveria ser pós-processada para a aplicação em particular. Por exemplo, a extração de valores de circulação ao longo da envergadura de uma asa é um processo que faz sentido apenas para aplicações aeronáuticas. Assim sendo, o autor declara que, esse processamento deve ser feito externamente ao programa principal. Ainda comenta que, na prática, nada impede que ambas as etapas de pós e de pré-processamento sejam realizadas dentro de um mesmo programa.

A motivação do autor para essa filosofia de implementação foi colocar o programa básico de análise numa forma genérica, abrindo a possibilidade de implementar diferentes programas de interface, cada qual voltado a um tipo de problema aerodinâmico em particular, utilizando, no entanto, o mesmo programa principal. Permitindo assim a ampliação das possibilidades de estudo.

Características gerais do método implementado.

1. Representação geométrica de singularidades de ordem reduzida, usando painéis planos com distribuições constantes de $\sigma$ e $\mu$. Apesar da simplicidade das operações envolvidas a generalidade não foi prejudicada, uma vez que todos os elementos de um método típico estão presentes.

2. Condição de contorno de Neumann para a velocidade normal à superfície $\mathrm{V}_{\mathrm{n}}$. A escolha dessa condição de contorno se deu devido à experiência do autor com métodos de malha de vórtices que aplicam essas condições (MARTINS, 1993), e à disponibilidade de material previamente elaborado.

VISUALIZAÇÃO CIENTIFICA COMPUTACIONAL APLICADA A MODELOS AERODINÂMICOS SIMULADOS EM MÉTODO DOS PAINEIS. 
3. Dois modelos de formulação alternativos. Sob a condição de Neumann havia duas possibilidades viáveis para a combinação de singularidades (formulação) a serem utilizadas formando dois modelos de singularidades possíveis. Um modelo que o autor chamou de A e outro B.

- Modelo A: painéis de fontes descrevem a superfície dos corpos e assumem o papel principal de garantir a condição de contorno para $V_{n}$, enquanto as intensidades de painéis de dipolos permitem introduzir circulação no escoamento. Este método é chamado "método de fontes superficiais".

- Modelo B: painéis de dipolos descrevem as superfícies dos corpos e assumem o papel principal de garantir a condição de contorno para $\mathrm{V}_{\mathrm{n}}$. No método implementado, decidiu-se adotar a formulação na qual os painéis da superfície também possuiriam distribuições adicionais de fontes. As intensidades $\sigma$ seriam ajustadas arbitrariamente por um fator $\eta$ para cancelar uma parcela da componente normal da velocidade do escoamento livre sobre o ponto de controle do respectivo painel. Assumindo-se os pontos de controle sobre os centróides dos painéis.

4. Condição de Kutta do tipo 1. (MARTINS,1997) Nessa forma a condição seria imposta colocando-se pontos de controle adicionais, ou pontos de Kutta para cada faixa da esteira de dipolos discretizada a uma pequena distância $\delta$ do bordo de fuga da superfície, sobre uma extensão da superfície média do aerofólio.

5. Esteiras de dipolos independentes. Partindo-se da idéia de que a condição de Kutta num aerofólio é uma forma "controlada" de separação do escoamento, sendo as esteiras de dipolos definidas como mallas de painéis independentes, ou seja, não necessariamente associadas às superfícies sustentadoras. Tendo como principais características:

- Topologia retangular, ou seja, a posição de um certo painel poderia ser definida por dois índices (i, j), tal como um elemento de uma matriz. Ao longo de um dos índices, cada coluna de painéis da malha manteria intensidade constante de dipolos $\mu_{w}$, definindo faixas de dipolos equivalentes a vórtices "em ferradura" as posições dos vértices.

- A intensidade $\mu_{w}$ associada a cada coluna seria obtida da solução do sistema linear. Apenas o primeiro painel de cada coluna teria um ponto de controle, a ser usado como ponto de Kutta, ou seja, seria um painel de Kutta. A geometria deste primeiro painel poderia ser ajustada para satisfazer as restrições da distancia $\delta$ entre os pontos de Kutta e o bordo de fuga de uma asa.

- Faixas semi-infinitas de dipolos seriam definidas por semi-retas alinhadas às arestas dos últimos painéis de cada coluna, os painéis direcionadores.

6. Três opções de modelagem de superfícies sustentadoras no modelo A para promover a continuidade de dipolos na junção da esteira com o bordo de fuga, para evitar uma singularidade local.

VISUALIZAÇÃO CIENTIFICA COMPUTACIONAL APLICADA A MODELOS AERODINÂMICOS SIMULADOS EM MÉTODO DOS PAINEIS. 
7. Cálculos de forças resultantes por integração e pressões e no plano de Trefftz, cobrindo as seguintes possibilidades:

- As componentes de força perpendiculares ao escoamento livre $U_{\infty}$, ou seja, sustentação $\mathrm{L}$ e força lateral $\mathrm{F}_{\mathrm{y}}$, seriam calculadas por integração de pressões superficiais, o mesmo ocorrendo para as três componentes do momento de rotação ao redor de um ponto de referencia dado.

- A componente na direção de $U_{\omega}$, ou seja, o arrasto induzido $\mathrm{D}_{\mathrm{i}}$, seria calculado por integração de pressões ou, opcionalmente, de saltos de velocidade no plano de Trefftz.

Em termos de integração de pressões na superfície, a força resultante sobre os corpos pode ser expressa por:

$$
\frac{F}{\frac{1}{2} \rho U_{\infty}^{2} S_{r e f}}=\frac{1}{S_{r e f}} \sum_{i=1}^{N s}-C_{P i} \hat{n}_{i} S_{i}
$$

Onde:

$\mathrm{S} \quad$ área superficial dos corpos

$\mathrm{S}_{\mathrm{ref}} \quad$ área de referencia arbitraria

$\mathrm{N}_{\mathrm{s}} \quad$ Número de painéis que definem a superfície dos corpos (não internos)

$\mathrm{C}_{\mathrm{Pi}} \quad$ Coeficiente de pressão associado ao painel $\mathrm{i}$.

$\mathrm{S}_{\mathrm{i}} \quad$ área superficial do painel $\mathrm{i}$.

$n_{\mathrm{i}} \quad$ versor normal ao painel $\mathrm{i}$.

O momento resultante $\mathrm{M}$ com relação a um dado ponto de referencia é calculado de maneira semelhante, porém envolve a distribuição de cada painel na forma de produtos vetoriais. Uma vez obtidos $\mathrm{F}$ e $\mathrm{M}$, suas componentes podem ser representadas em quaisquer direções. No caso do escoamento livre uniforme, define-se um sistema orientado pelo escoamento e portanto as componentes na forma de coeficiente $C_{\mathrm{L}}, \mathrm{C}_{\mathrm{Di}}$ e $\mathrm{C}_{\mathrm{y}}$ para a força e $\mathrm{C}_{\mathrm{mx}}, \mathrm{C}_{\mathrm{my}}$ e $\mathrm{C}_{\mathrm{mz}}$ para o momento. No trabalho do autor adotou-se as conclusões de (SMITH \& KROO, 1993), segundo as quais a consideração da esteira de dipolos como orientada na direção de $U_{\infty}$ é teoricamente capaz de fornecer resultados exatos para $\mathrm{C}_{\mathrm{Di}}$, pelo menos para superfícies sustentadoras isoladas. Assim, adotou-se a hipótese provisória de que a intersecção da esteira com o plano de Trefftz seria representada pela projeção da linha do bordo de fuga da asa na direção de $U_{\infty}$. Esta aproximação foi assumida mesmo quando a esteira não tinha aquela orientação, o que pode ser considerado válido para superfícies isoladas em baixos ângulos de ataque.

As principais características do método implementado foram sintetizadas na Figura A.1. Observa-se a subdivisão do Modelo A nas formas A1, A2 e A3, como opções para representar escoamentos com circulação ao redor de superfícies sustentadoras. 


\section{Condição de Contorno na Superfície: Neumann}
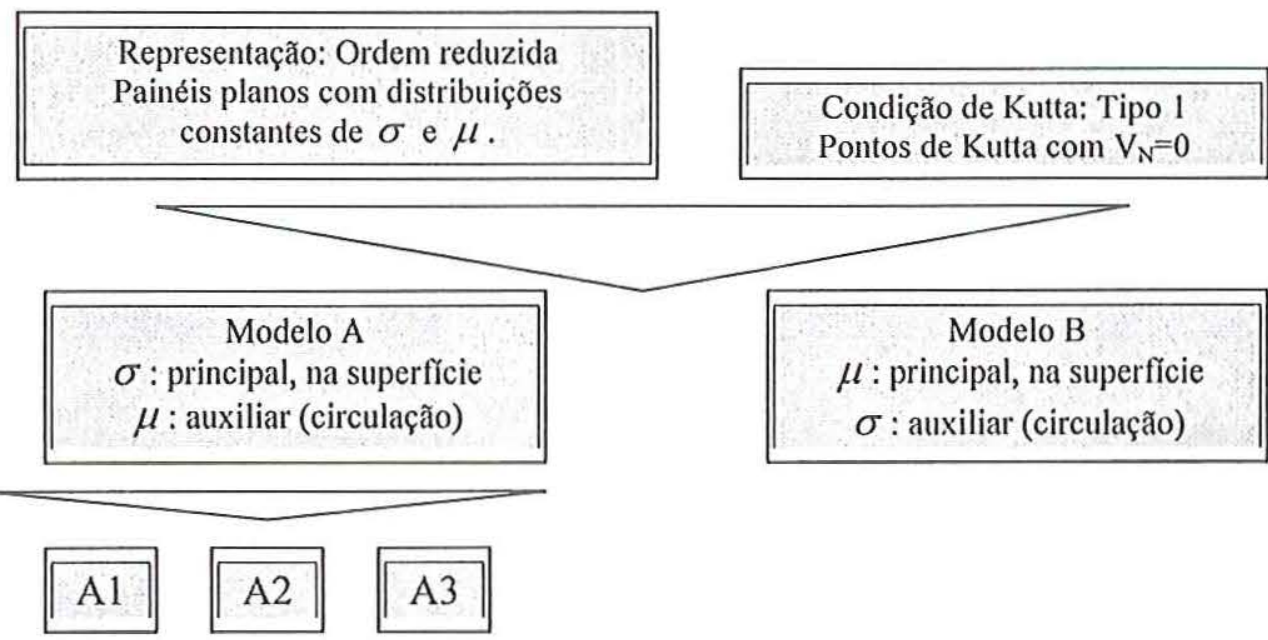

FIGURA A.1- Características gerais do método implementado.

Outras características importantes do método implementado.

- Os painéis são organizados em malhas independentes. Cada malha é associada a um identificador que define seu tipo (de fontes, dipolos, esteira, etc). Todas possuem topologia retangular, ou seja, a posição de qualquer painel pode ser definida por um par de índices (i, j).

- Duas formas opcionais de correção de compressibilidade, ambas descritas na dissertação do autor.(MARTINS, 1997)

- Prandtl-Glauert.

- Prandtl-Glauert modificada, segundo a proposta de (KRAUS, 1978).

- Tratamento de escoamentos simétricos por reflexão com relação ao plano $\mathrm{XZ}$ e/ou ao plano $\mathrm{XY}$ do sistema de coordenadas, para reduzir custo computacional.

- Utilização de expansões multipólo (singularidades puntuais) para as expressões das velocidades induzidas pelos painéis sobre pontos a maiores distâncias, para reduzir custo computacional. 


\section{MANUAIS APÊNDICE B}




\section{Manuais}

\subsection{Panflo 2.0}

1.1.1. Exemplo de formato de arquivo de entrada de dados gerais (extensão pfi).

PFLO Panel Method Analisys Input File

Test Case: Paturi Wing Body.

1

$11110 \quad$ Output keys: GD CP PGF ACAD VTK

Aerodynamic and Reference Data:

$0.00 \quad 0.002 .00 \quad$ ALPHA1, ALPHA2, DALPHA

$0.00 \quad$ YAW

0.00 ROLL

$0.00 \quad \mathrm{MACH}$

16. $6670 \quad$ Sref

$1.01000 \quad$ Cref

$0.00 \quad$ xref

$0.00 \quad$ Yref

$0.00 \quad$ Zref

Mesh and Processing Data:

1 Sym

1 Lin

3 VM: Vortex mesh arrangement id.

$0.0 D 0 \quad$ WAKEDIR

$0.005 \mathrm{DO}$

1. DO KTV

11 NdivI NdivJ

$320 \quad$ MWBM (Width for internal body meshes)

$1 \quad$ Number of mesh files

'PaturiWB3.pfg ' Mesh files names

FIGURA B.1. - Exemplo de arquivo "pfi". 
A seguir é exibida uma tabela com a descrição das funções de cada variável do arquivo pfi disponibilizada pelo autor (MARTINS, 1997).

\begin{tabular}{|c|c|c|c|}
\hline Variable & Type & Default & Description \\
\hline Process & Integer & N/A & $\begin{array}{l}\text { Identifier for program run task: } \\
<=1 \text { : full run (geometry + flow computation) } \\
>=2 \text { : geometry check run. }\end{array}$ \\
\hline GD & Logical & N/A & $\begin{array}{l}\text { Indicates creation of general data output file } \\
\text { (aerodynamic forces and spanwise distribution of } \\
\text { coefficients). }\end{array}$ \\
\hline $\mathrm{CP}$ & Logical & N/A & $\begin{array}{l}\text { Indicates creation of surface coefficients file. } \\
\text { (CP, local velocities, etc.). }\end{array}$ \\
\hline PGF & Logical & N/A & $\begin{array}{l}\text { Indicates creation of panel geometry file. Used for } \\
\text { geometry checking purposes. }\end{array}$ \\
\hline ACAD & Logical & N/A & $\begin{array}{l}\text { Indicates creation of AUTOCAD script file, for panel } \\
\text { geometry visualization check purposes. }\end{array}$ \\
\hline VTK & Logical & N/A & $\begin{array}{l}\text { Indicates creation of Visualization Tool Kit data file for } \\
\text { visualization of pressure distributions. }\end{array}$ \\
\hline ALPHA1 & Real & N/A & Initial value of the range of angle of attack for analysis. \\
\hline ALPHA2 & Real & N/A & Final value of the range of angle of attack for analysis. \\
\hline DALPHA & Real & N/A & $\begin{array}{l}\text { Increment of angle of attack to define analysis values } \\
\text { between ALPHA1 and ALPHA2. }\end{array}$ \\
\hline YAW & Real & 0.0 & $\begin{array}{l}\text { Angle of yaw (sideslip), between the freestream velocity } \\
\text { vector and the } \mathrm{XZ} \text { geometry plane. }\end{array}$ \\
\hline ROLL & Real & 0.0 & $\begin{array}{l}\text { Angle of roll, between the freestream velocity vector and } \\
\text { the XY geometry plane. }\end{array}$ \\
\hline $\mathrm{MACH}$ & Real & N/A & $\begin{array}{l}\text { Mach number, for application of the Prandtl-Glauert } \\
\text { linearized compressibility correction. }\end{array}$ \\
\hline SREF & Real & N/A & $\begin{array}{l}\text { Reference area for calculation of aerodynamic force } \\
\text { coefficients. }\end{array}$ \\
\hline CREF & Real & N/A & $\begin{array}{l}\text { Reference length for calculation of the aerodynamic } \\
\text { moment coefficients. }\end{array}$ \\
\hline $\begin{array}{l}\text { XREF } \\
\text { YREF } \\
\text { ZREF }\end{array}$ & Real & N/A & $\begin{array}{l}\text { Cartesian coordinates of the reference point in space } \\
\text { around which the aerodynamic moment coefficients will } \\
\text { be computed. }\end{array}$ \\
\hline SYM & Logical & N/A & $\begin{array}{l}\text { Indicates if a symmetry condition is to be imposed at the } \\
\mathrm{XZ} \text { geometry plane: } \\
\text { - Must be .TRUE. when half geometry is input (see } \\
\text { geometry input below). } \\
\text { - If .TRUE., then ROLL and YAW must be zero. }\end{array}$ \\
\hline LIN & Logical & .TRUE. & $\begin{array}{l}\text { Indicates if linearization condition for angles can be } \\
\text { applied (reducing processing time). Generally, } \\
\text { linearization can be applied to angles within }[-5,5] \\
\text { degrees. }\end{array}$ \\
\hline
\end{tabular}




\begin{tabular}{|c|c|c|c|}
\hline Variable & Type & Default & Description \\
\hline VM & Integer & $\begin{array}{l}\text { Not } \\
\text { equal to } \\
2\end{array}$ & $\begin{array}{l}\text { Vortex mesh arrangement identification, used for } \\
\text { automatic vortex mesh generation on lifting surface } \\
\text { panel meshes: } \\
0=\text { no vortex mesh (case without circulation); } \\
1=\text { internal mesh, fixed subdivision; } \\
2=\text { internal mesh, automatic subdivision; } \\
3=\text { surface doublet mesh. }\end{array}$ \\
\hline FST & Logical & $\begin{array}{c}\text {.FALSE } \\
.\end{array}$ & $\begin{array}{l}\text { Fixed chordwise vortex distribution key: } \\
\text {.TRUE. = a fixed distribution function for vortex } \\
\text { strength along the J mesh index direction is assumed, } \\
\text { for reduction of processing time. } \\
\text {.FALSE. = no vortex distribution model assumed } \\
\text { (safer for general lifting surface geometries.) }\end{array}$ \\
\hline WAKEDIR & Real & 1.0 & $\begin{array}{l}\text { Defines the direction for the trailing vortex wakes, } \\
\text { when they are generated in automatic mode }(V M>0) \text { : } \\
=0.0 \text { for free-stream flow direction. } \\
=1.0 \text { for alignment with the mean camber surface of } \\
\text { the lifting surfaces airfoils. } \\
0.0<\text { WAKEDIR }<1.0 \text { for direction in between the } \\
\text { extreme cases above. }\end{array}$ \\
\hline KKT & Real & 0.005 & $\begin{array}{l}\text { Streamwise size of the Kutta panels used in automatic } \\
\text { vortex and wake mesh generation, relative to the local } \\
\text { lifting surface streamwise chord. }\end{array}$ \\
\hline KTV & Real & 1.0 & $\begin{array}{l}\text { Streamwise size of the Kutta panels used in automatic } \\
\text { vortex and wake mesh generation, relative to the local } \\
\text { lifting surface streamwise chord. }\end{array}$ \\
\hline $\begin{array}{l}\text { NDIVI } \\
\text { NDIVJ }\end{array}$ & Integer & $\begin{array}{l}1 \\
1\end{array}$ & $\begin{array}{l}\text { Number of subdivisions used in the I and } \mathrm{J} \text { index } \\
\text { directions for refinement of the internal vortex } \\
\text { meshes. Used only if VM=2 (not recommended). }\end{array}$ \\
\hline MWBM & Integer vector & N/A & $\begin{array}{l}\text { Vector of mesh sizes in the I direction to be used for } \\
\text { automatic generation of internal vortex meshes at } \\
\text { wing/body intersections. If the last value is input as } \\
\text { zero, all subsequent intersections found in the input } \\
\text { geometry will be generated using the last non-zero } \\
\text { vector element. }\end{array}$ \\
\hline $\begin{array}{l}\text { Number of } \\
\text { mesh files }\end{array}$ & Integer & N/A & $\begin{array}{l}\text { Number of geometry files for the meshes to be read. } \\
\text { All the geometries read will compose the } \\
\text { configuration to be analised. }\end{array}$ \\
\hline $\begin{array}{l}\text { Mesh file } \\
\text { names }\end{array}$ & Character & N/A & $\begin{array}{l}\text { Names of geometry files for the meshes to be read. } \\
\text { All the geometries read will compose the } \\
\text { configuration to be analised. The names must be input } \\
\text { in a sequence, one per line. }\end{array}$ \\
\hline
\end{tabular}


1.1.2. Exemplo do formato do arquivo dados de entrada da geometria (extensão PFG):

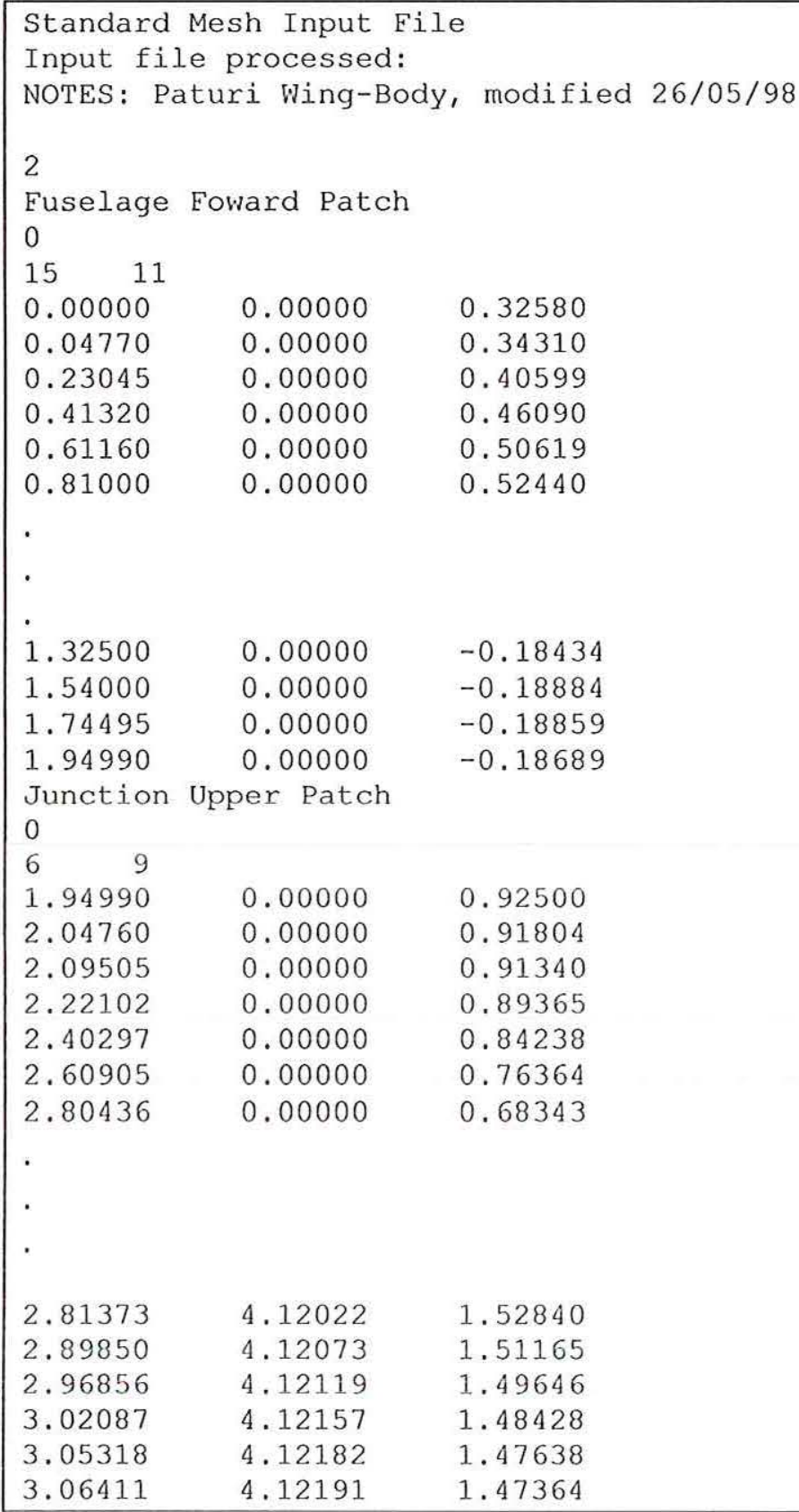

FIGURA B.2. - Exemplo de arquivo "pfg".

A seguir é exibida uma descrição do arquivo pfg disponibilizada pelo autor (MARTINS, 1997). 
Geometry file format description:

\section{Lines 1 to 4:}

Lines available for titles and comments (ignored during file reading).

Line 5:

Integer: number of panel meshes NM described in the present geometry file.

\section{Below line 5:}

Geometry is described in NM blocks, each one of them containing the geometry of one of the NM panel meshes. A panel mesh block that starts at line $\mathrm{K}$ has the following format:

Line K:

Character: name of the patch, for reference.

Line $(\mathrm{K}+1)$ :

Integer: identifier MTYPE for the type of mesh being read:

MTYPE < 0: options for automatic generation for vortex meshes on lifting surfaces.

MTYPE > 0: the value indicates directly the kind of singularity to be used on the patch.

Mesh types available for PanFlo 2.0 are, according to MTYPE:

\begin{tabular}{|c||l|}
\hline MTYPE & Mesh Type \\
\hline-3 & Lifting surface mesh, not intersecting a body \\
\hline-2 & Lifting surface mesh, intersecting a body \\
\hline-1 & Body/surface intersection meshes (not lifting) \\
\hline 0 & Body meshes (not lifting) \\
\hline 1 & Source panel mesh \\
\hline 2 & Vortex panel mesh \\
\hline 3 & Wake vortex panel mesh \\
\hline 4 & Fixed strength vortex panel mesh \\
\hline 5 & Source/vortex panel mesh \\
\hline
\end{tabular}

Line $(K+2)$ :

Integer: sizes of the panel mesh $\mathrm{M}$ and $\mathrm{N}$, respectively along the $\mathrm{I}$ and $\mathrm{J}$ index directions. These indicate that the current mesh has $\mathrm{M} \times \mathrm{N}$ panels, defined by $(\mathrm{M}+1) \times(\mathrm{N}+1)$ vertex points.

From line $\mathrm{K}+3$ to line $\mathrm{K}+2+(\mathrm{M}+1)(\mathrm{N}+1)$ :

Real: cartesian coordinates $\mathrm{X}, \mathrm{Y}$ and $\mathrm{Z}$ for each vertex point that define the current panel mesh. The points are displayed across the $J$ index, for each of the I index values. From a FORTRAN 77 program, the points could be read by a DO loop set of the type:

DO $\mathrm{I}=1, \mathrm{M}$

$$
\text { DO } \mathrm{J}=1, \mathrm{~N}
$$

$$
\text { READ X(I,J), Y(I,J), Z(I,J) }
$$

\section{END DO}

$$
\text { END DO }
$$

VISUALIZAÇÃO CIENTIFICA COMPUTACIONAL APLICADA A MODELOS AERODINÂMICOS SIMULADOS EM MÉTODO DOS PAINEIS. 


\subsection{Como executar o programa.}

Depois de criados os arquivos acima um executável com o nome de "panflo20" deve ser aberto aparecendo a tela que é mostrada na Figura B.3., que é onde o programa pede para o usuário informar quais arquivos ele deve ler. Deve ser colocado o nome do arquivo pfi sem a extensão. Em seguida o software realiza os cálculos e processa as saídas.

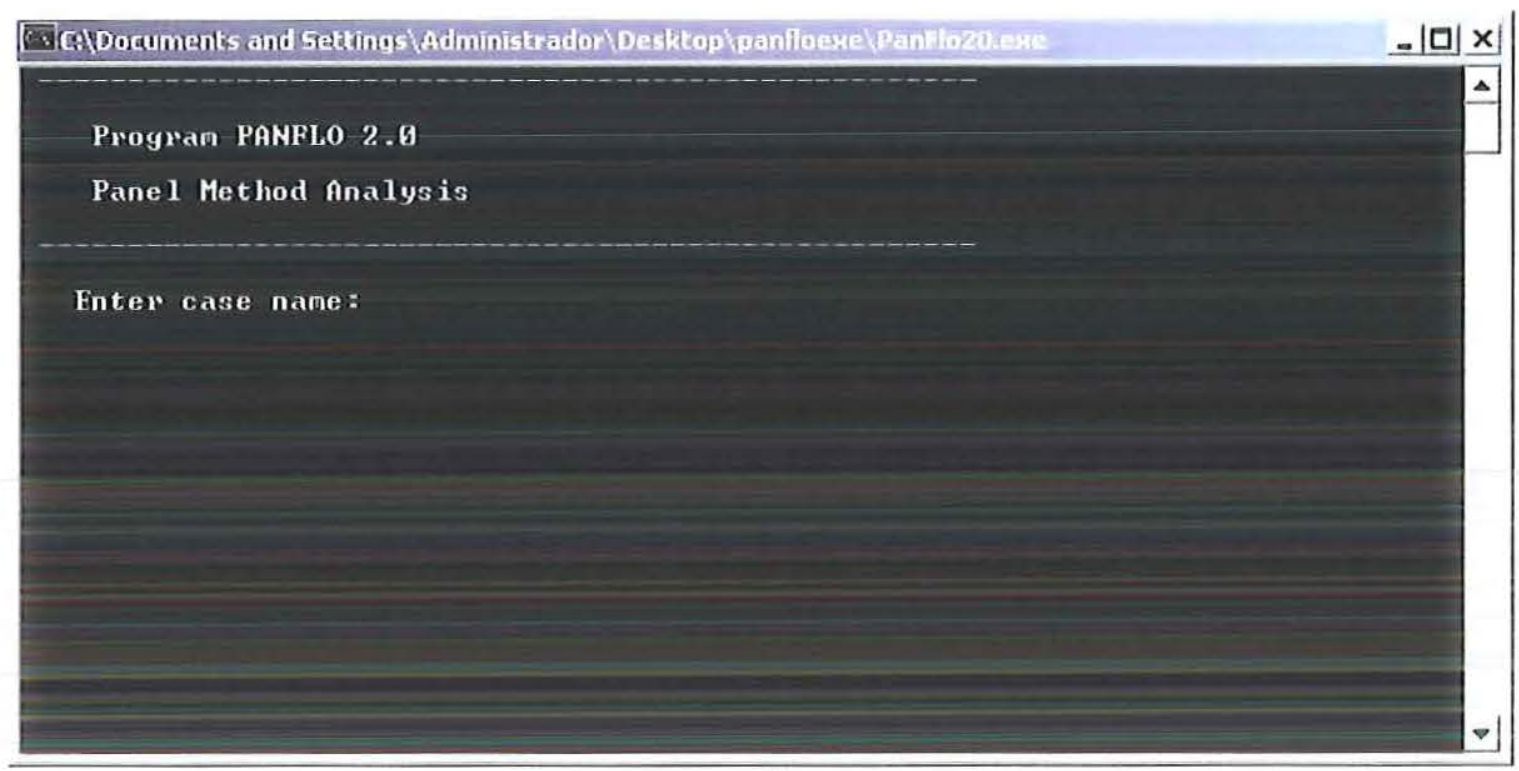

FIGURA B.3. - Tela de entrada do PanFlo20.

\subsection{Arquivos de Saída.}

Os arquivos de saída gerados dependem de quais tipos de arquivos foram setados como 1 no arquivo "pfi" criado. Na linha onde são encontrados os seguintes comandos:

\section{$11110 \quad$ Output keys: GD CP PGF ACAD VTK.}

O Número 1 seta como sim e 0 seta como não, como descrito na tabela de descrição das variáveis. 
Além dos resultados numéricos (extensão pfo e pcp), o programa cria um script que pode ser aberto em AutoCad para a visualização da malha de painéis gerada pelo programa e um arquivo em formato VTK para visualização dos cálculos de CP na superfície do corpo calculado.

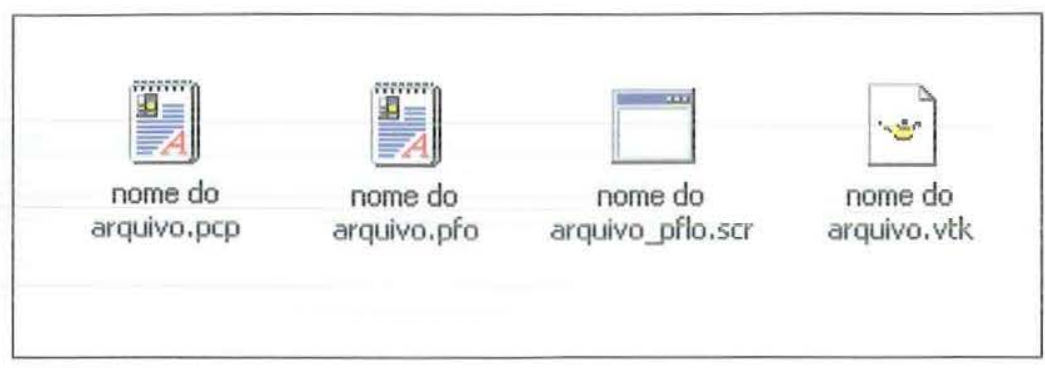

FIGURA B.4. - Arquivos de Saída.

\subsection{Instruções para utilizar o VTK, versão 3.1, no MS Visual C +十.}

Uma vez de posse do CD Bibliotecas, anexo ao manual, vamos seguir os passos:

1. Salvar a biblioteca vtkdll.dll (contida no CD) no diretório System32 do Windows.

2. Dentro do $\mathrm{C}++$, abrir um projeto do tipo Win32 Console Application.

3. Incluir as bibliotecas necessárias:

Em Project -> Settings $\rightarrow$ Link, e digitar no campo Object/Library modules, logo no inicio do campo, as bibliotecas a serem incluidas, opengl32.lib e glaux.lib.

Em Project ->Add to Project-> Files, adicionar a vtkdll.lib (contida no CD).

4. Adicionar os diretórios dos 'headers' do VTK nos caminhos de diretórios do Compilador: - Supondo que você colocou o CD do VTK no drive F: Em Tools $\rightarrow>$ Options - > Directories, adicionar os seguintes diretórios:

F:IVTK3.1\CONTRIB

F:IVTK3.1\PATENTED

F:IVTK3.1 IMAGING

F:VTK3.1\GRAPHICS

F:IVTK3.1\COMMON 